ournal for ImmunoTherapy of Cancer

\section{Immune checkpoint silencing using RNAi-incorporated nanoparticles enhances antitumor immunity and therapeutic efficacy compared with antibody-based approaches}

To cite: Won JE, Byeon Y, Wi TI, et al. Immune checkpoint silencing using RNAiincorporated nanoparticles enhances antitumor immunity and therapeutic efficacy compared with antibodybased approaches. Journal for ImmunoTherapy of Cancer 2022;10:e003928. doi:10.1136/ jitc-2021-003928

- Additional supplemental material is published online only. To view, please visit the journal online (http://dx.doi.org/10. 1136/jitc-2021-003928).

Y-MP and HDH are joint senior authors.

Accepted 30 January 2022

\section{ABSTRACT}

Background Cytotoxic $C D 8^{+} T$ cell-based cancer immunotherapy has been extensively studied and applied, however, tumor cells are known to evade immune responses through the expression of immune checkpoints, such as programmed death ligand 1 (PD-L1). To overcome these issues, antibody-based immune checkpoint blockades (eg, antiprogrammed cell death 1 (anti-PD-1) and anti-PD-L1) have been revolutionized to improve immune responses. However, their therapeutic efficacy is limited to $15 \%-20 \%$ of the overall objective response rate. Moreover, PD-L1 is secreted from tumor cells, which can interrupt antibody-mediated immune reactions in the tumor microenvironment.

Methods We developed poly(lactic-co-glycolic acid) nanoparticles (PLGA-NPs) encapsulating PD-L1 small interfering RNA (siRNA) and PD-1 siRNA, as a delivery platform to silence immune checkpoints. This study used the TC-1 and EG7 tumor models to determine the potential therapeutic efficacy of the PLGA (PD-L1 siRNA+PD-1 siRNA)-NPs, on administration twice per week for 4 weeks Moreover, we observed combination effect of PLGA (PD-L1 siRNA+PD-1 siRNA)-NPs and PLGA (antigen+adjuvant)NPs using TC-1 and EG7 tumor-bearing mouse models. Results PLGA (PD-L1 siRNA+PD-1 siRNA)-NPs boosted the host immune reaction by restoring $\mathrm{CD}^{+} \mathrm{T}$ cell function and promoting cytotoxic $\mathrm{CD} 8^{+} \mathrm{T}$ cell responses. We demonstrated that the combination of NP-based therapeutic vaccine and PLGA (siRNA)-NPs resulted in significant inhibition of tumor growth compared with the control and antibody-based treatments $(p<0.001)$. The proposed system significantly inhibited tumor growth compared with the antibody-based approaches. Conclusion Our findings suggest a potential combination approach for cancer immunotherapy using PLGA (PD-L1 siRNA+PD-1 siRNA)-NPs and PLGA (antigen+adjuvant)NPs as novel immune checkpoint silencing agents. permitted under CC BY. Published by BMJ.

For numbered affiliations see end of article.

Correspondence to

Dr Hee Dong Han;

hanhd8848@naver.com

\section{BACKGROUND}

Cancer immunotherapy is an exciting therapeutic approach that has seen tremendous advances in recent years for various types of cancer. ${ }^{1}$ These approaches have focused on improving the immunological function of cytotoxic T cells. ${ }^{2}$ Among novel immunotherapeutic strategies, immune checkpoint inhibitors such as antibody-based programmed death ligand 1 (anti-PD-L1) and programmed cell death 1 (anti-PD-1) have shown effectiveness against a large number of cancer types. ${ }^{3}$ PD-L1 is expressed on the surface of various cells, including macrophages and dendritic cells (DCs). ${ }^{4}$ In particular, PD-L1 is abundantly expressed in various tumor cells such as lung, ${ }^{5}$ colon, ${ }^{6}$ melanoma,${ }^{7}$ and leukemic cells, ${ }^{8}$ and contributes to immune escape through its interaction with PD-1 on cytotoxic T cells. ${ }^{2}$ Moreover, recent studies have revealed the intrinsic expression of PD-1 in tumor cells. PD-1 can activate the expression of PD-L1 in tumor cells by means of crossreactive stimulation, leading to the promotion of cell growth regardless of adaptive immunity. ${ }^{910}$

Although anti-PD-L1 or anti-PD-1 blockade is currently approved to treat cancers, the overall response rates are limited to $<20 \%$ of patients. ${ }^{11}$ More importantly, PD-L1 and PD-1 can be secreted from tumor cells into the tumor microenvironment in a soluble form, which may lead to reduced therapeutic efficacy for antibody blockades. ${ }^{12}$ The immunosuppressive function of secreted PD-L1 in blood circulation has been highly correlated with poor prognosis in multiple cancers. ${ }^{13}$ These secreted PD-L1 increase the complexity and diversity of the PD-1/PD-L1 signaling pathway composition. ${ }^{12}$ Eventually, the secretion of PD-1 or PD-L1 from tumor cells or T cells competitively interrupts the neutralizing 
activity of antibody-based blockade and induces resistance. ${ }^{14}$ To overcome these hurdles, we hypothesized that immune checkpoint silencing might be a better strategy for enhancing therapeutic efficacy than immune checkpoint blocking.

Therefore, in this study, we propose a small interfering RNA (siRNA)-based immune checkpoint silencing system. The advantages of the siRNA approach include target-specific gene silencing compared with other small molecules or antibody-based approaches. ${ }^{15}$ Despite the therapeutic potential of siRNA, siRNA delivery has led to issues in clinical applications due to its rapid degradation after intravenous injection. Therefore, an effective delivery platform is essential for the use of siRNA. ${ }^{16} \mathrm{We}$ selected the poly(lactic-co-glycolic acid) (PLGA) nanoparticle (NP) system as the siRNA delivery platform, which is a particularly attractive option for clinical and biological applications, because of its low toxicity, low immunogenicity, biocompatibility, and biodegradability. ${ }^{178}$

To extend our concept, we combined the PLGA-NPbased therapeutic vaccine system with tumor antigens and adjuvants. ${ }^{19} 20$ This approach was selected because of the increased efficiency of intracellular delivery of tumor antigens and adjuvants to DCs, induction of DC maturation, and activation of cytotoxic $\mathrm{CD} 8^{+} \mathrm{T}$ cells via antigen-specific cross-presentation, leading to increased tumor-specific cytotoxic $\mathrm{CD} 8^{+} \mathrm{T}$ cell responses.

In the present study, we suggest novel strategies for siRNA-based immune checkpoint silencing systems that inhibit the expression of secreted PD-L1 in the tumor microenvironment. Moreover, the PLGA-NP-based vaccine system enhanced additional antigen-specific $\mathrm{CD}^{+} \mathrm{T}$ cell responses, leading to increased synergistic antitumor responses. These approaches provide a novel combination for cancer immunotherapy that resulted in improved therapeutic efficacy.

\section{MATERIALS AND METHODS \\ Materials}

PLGA (resomer RG502H, monomer ratio: 50:50, molecular weight (MW): 7-17 kDa), polyvinyl alcohol (PVA, $80 \%$ hydrolyzed, MW: 9-10 kDa), ovalbumin (OVA), polyinosinic-polycytidylic acid sodium salt (poly I:C), and poly-L-lysine (PLL) were purchased from SigmaAldrich (St. Louis, Missouri, USA). All other materials were of analytical grade and were used without further purification. The CD8 $\mathrm{a}^{+}$T cell isolation kit was purchased from Miltenyl Biotec (Bergisch Gladbach, Germany). Carboxyfluorescein diacetate succinimidyl ester (CFSE) and SYTOX Green were purchased from Thermo Scientific (Waltham, Massachusetts, USA). Antimouse PD-1 (CD279) and antimouse PD-L1 (B7-H1) were purchased from Bio X Cell (West Lebanon, New Hampshire, USA). Recombinant mouse interferon-gamma (IFN- $\gamma$ ) and recombinant human IFN- $\gamma$ were purchased from ProSpec (Rehovo, Israel). Fluorescein isothiocyanate (FITC)-mIFN- $\gamma$ and PE-mPD-1 antibody, as well as, IFN- $\gamma$ and interleukin-2 (IL-2) ELISA kits were purchased from eBioscience (San Diego, California, USA). APCconjugated CD4, CD8, CD11c, F4/80, mPD-L1, hPD-L1, and PE-CD3 antibodies were purchased from BioLegend (San Diego, California, USA). The PD-L1 ELISA kit was purchased from R\&D Systems (Minneapolis, Minnesota, USA). Cy5-conjugated granzyme B and FITC-conjugated CD107a antibodies were purchased from Bioss (Woburn, Massachusetts, USA). CD3 and CD28 antibodies were purchased from BD Biosciences (San Jose, California, USA). PD-1 and PD-L1 antibodies were purchased from Novus (Littleton, Colorado, USA). CD8, Ki67, and matrix metalloproteinase-9 (MMP-9) antibodies were purchased from Abcam (Cambridge, UK). The proliferating cell nuclear antigen (PCNA) antibody was purchased from Cusabio (Houston, Texas, USA). Terminal deoxynucleotidyl transferase dUTP nick end labeling (TUNEL) assay kit was purchased from TREVIGEN (TACS 2 TdT DAB Kit, Gaithersburg, Maryland, USA). RPMI 1640 and fetal bovine serum (FBS) were acquired from Biowest (Nuaille, France). Opti-MEM and hanks balanced salt solution (HBSS) were acquired from Thermo Fisher Scientific (Waltham).

\section{Preparation of PLGA (PD-L1 siRNA+PD-1 siRNA)-NPs}

We prepared PLGA (PD-L1 siRNA+PD-1 siRNA)-NPs using a water-in-oil-in-water $(\mathrm{w} / \mathrm{o} / \mathrm{w})$ double emulsion solvent evaporation method. ${ }^{21}$ Briefly, $125 \mu \mathrm{g}$ of PD-1 siRNA, $125 \mu \mathrm{g}$ of PD-L1 siRNA, and $187.5 \mu \mathrm{g}$ of PLL were dissolved in $0.2 \mathrm{~mL}$ of RNase-free water. This mixture was added dropwise to $2 \mathrm{~mL}$ of chloroform containing $40 \mathrm{mg}$ of PLGA using a probe-type sonicator (Sonics \& Materials) at $4^{\circ} \mathrm{C}$ for $1 \mathrm{~min}(20$ pulses of $5 \mathrm{~s}$, with a $3 \mathrm{~s}$ gap). The primary emulsion was further emulsified with a secondary water phase $(10 \mathrm{~mL}$ of $1.0 \% \mathrm{w} / \mathrm{v}$ PVA $)$ at $4^{\circ} \mathrm{C}$ for $10 \mathrm{~min}$. The chloroform was evaporated using a rotary evaporator at $25^{\circ} \mathrm{C}$ under vacuum. After evaporation, the PLGA-NPs were washed three times by means of centrifugation at 13,000 rpm for $20 \mathrm{~min}$, and stored at $4^{\circ} \mathrm{C}$ until use.

PLGA-NP vaccine containing both antigen (OVA or E7 peptide) and adjuvant (poly I:C) was prepared using the $\mathrm{w} / \mathrm{o} / \mathrm{w}$ double emulsion solvent evaporation method. Briefly, $1 \mathrm{mg}$ antigen (OVA or E7 peptide) and $2 \mathrm{mg}$ poly $\mathrm{I}: \mathrm{C}$ were dissolved in $0.2 \mathrm{~mL}$ deionized water and mixed with $2 \mathrm{~mL}$ chloroform containing $40 \mathrm{mg}$ PLGA using a probe-type sonicator, at $4^{\circ} \mathrm{C}$ for $1 \mathrm{~min}$ (20 pulses of $5 \mathrm{~s}$, with a $3 \mathrm{~s}$ gap). The primary emulsion was further emulsified with a secondary aqueous phase $(10 \mathrm{~mL}$ of $1.0 \%$ $\mathrm{w} / \mathrm{v}$ PVA) at $4^{\circ} \mathrm{C}$ for $10 \mathrm{~min}$, to form a secondary emulsion. To completely remove the chloroform, the emulsion was evaporated using a rotary evaporator, at $25^{\circ} \mathrm{C}$ under vacuum. After evaporation, the suspension of PLGA-NPs was washed three times with deionized water at $4^{\circ} \mathrm{C}$ by means of centrifugation at 13,000 rpm for $20 \mathrm{~min}$.

The loading efficiency of FITC-labeled siRNA into PLGA-NPs and release behavior were determined using a fluorescence spectrophotometer (RF-5310PC, Shimadzu) 
at $488 \mathrm{~nm} .{ }^{21}$ The size and surface charge of the PLGA-NPs were measured using dynamic light scattering with an electrophoretic light scattering photometer (SZ-100, Horiba) ${ }^{22}{ }^{23}$ The morphology of PLGA-NPs was observed using scanning electron microscopy (SEM, Inspect F50, FEI, Hillsboro).

\section{Cell lines and siRNA}

TC-1 cells expressing HPV16 and HPV-E7 proteins and OVA-expressing EG7 cells (EL4 cell line transfected with the gene encoding OVA) were cultured in RPMI 1640 medium supplemented with $10 \% \mathrm{FBS}$ and $0.1 \%$ gentamycin. PD-1 siRNA (sense: CACUUCUAGGGACUUGAGA, antisense: UCUCAAGUCCCUAGAAGUG), PD-L1 siRNA (sense: GACUCAAGAUGGAACCUGA, antisense: UCAGGUUCCAUCUUGAGUC), and control siRNA (sense: TTCTCCGAACGTGTCACGT, antisense: ACGTGACACGTTCGGAGAA) were purchased from Sigma-Aldrich.

\section{Stimulation of $\mathrm{CD8}^{+} \mathrm{T}$ cells and tumor cells}

$\mathrm{CD}^{+} \mathrm{T}$ cells were isolated from splenocytes of C57BL/ 6 mice using a CD8 $\mathrm{a}^{+} \mathrm{T}$ cell isolation kit with AutoMACS purification, and confirmed by means of staining with PE-anti-CD3 and APC-anti-CD8. ${ }^{24}$ The $\mathrm{CD}^{+}{ }^{+} \mathrm{T}$ cells were stimulated in 24-well plates coated with $0.5 \mu \mathrm{g} /$ $\mathrm{mL}$ anti-CD3 and $5 \mu \mathrm{g} / \mathrm{mL}$ anti-CD28 in phosphatebuffered saline (PBS), overnight at $4^{\circ} \mathrm{C}$, and washed twice with $\mathrm{PBS}$ prior to use. $\mathrm{CD} 8^{+} \mathrm{T}$ cells were incubated for 24 hours at $37^{\circ} \mathrm{C}$ in an incubator containing $5 \% \mathrm{CO}^{2}$ Finally, we chose $\mathrm{CD} 8^{+} \mathrm{T}$ cells that showed expression of PD-1 by means of PE-anti-PD-1 staining. TC-1 tumor cells were stimulated in 6-well plates with the addition of 10 $\mathrm{nM}$ recombinant mouse IFN- $\gamma$ for 24 hours at $37^{\circ} \mathrm{C}$ in an incubator containing $5 \% \mathrm{CO} .{ }^{2}$ Tumor cells were determined by assessing the expression of PD-L1 using APCanti-PD-L1 staining.

\section{Intracellular delivery of PLGA (FITC-siRNA)-NPs}

Prior to testing the intracellular delivery of PLGA-NPs, we incorporated FITC-siRNA into PLGA-NPs. Briefly, CD $8^{+} \mathrm{T}$ cells, DCs, and tumor cells (TC-1 and EG7) were incubated in RPMI 1640 containing 10\% FBS with PLGA (FITC-siRNA)-NPs for $30 \mathrm{~min}$ at $37^{\circ} \mathrm{C}$. After incubation, the intracellular delivery efficiency of PLGA (FITCsiRNA)-NPs was determined using flow cytometry (FACSCalibur with CELLQuest software; BD Biosciences). Additionally, we observed intracellular delivery using confocal microscopy (LSM710, Carl Zeiss). The cells were incubated with PLGA (rhodamine-siRNA)-NPs for $30 \mathrm{~min}$ at $37^{\circ} \mathrm{C}$, washed with PBS, fixed with $4 \%$ (w/v) paraformaldehyde for $10 \mathrm{~min}$ at $25^{\circ} \mathrm{C}$, and stained with $1 \mathrm{mM}$ SYTOX Green in PBS for $10 \mathrm{~min}$.

\section{Immune checkpoint silencing using PLGA (PD-L1 siRNA+PD-1 SiRNA)-NPs}

Prior to determining the silencing effect, $\mathrm{CD} 8^{+} \mathrm{T}$ cells were stimulated using anti-CD3 and anti-CD28 to increase PD-1 expression on CD8 ${ }^{+}$T cell surfaces. TC-1 tumor cells were stimulated with IFN- $\gamma$ to induce PD-L1 expression.
Following that, $\mathrm{CD} 8^{+} \mathrm{T}$ cells $\left(5 \times 10^{6}\right)$ were incubated with PLGA (PD-L1 siRNA+PD-1 siRNA)-NPs (2 $\mu$ g of PD-1 siRNA and $2 \mu \mathrm{g}$ of PD-L1 siRNA) in Opti-MEM medium. TC-1 cells or DCs $\left(5 \times 10^{5}\right)$ were seeded into 6-well plates and incubated overnight. The cells were transfected with PLGA (PD-L1 siRNA+PD-1 siRNA)-NPs (2 $\mu \mathrm{g}$ of PD-1 siRNA and $2 \mu \mathrm{g}$ of PD-L1 siRNA) in Opti-MEM. The effect of immune checkpoint silencing was determined using western blot analysis and flow cytometry.

TC- 1 and EG7 cells were stimulated with IFN- $\gamma$ to induce PD-L1 expression. Cells $\left(5 \times 10^{5}\right)$ were seeded into 6 -well plates and incubated overnight. The cells were treated with PLGA (PD-L1 siRNA)-NPs (2 $\mu$ g of PD-L1 siRNA) in Opti-MEM for 72 hours. The tumor-conditioned media (TCM) was collected and centrifuged at $1500 \mathrm{rpm}$ for 3 min. Secreted PD-L1 expression in tumor cells was determined by measuring its levels in the TCM using western blot analysis.

Female C57BL/6 mice (5-6 weeks old, 20 g) were purchased from Orient Bio (Gapyeong, South Korea).

To generate tumors, TC- 1 cells $\left(1 \times 10^{6}\right.$ cells per $0.1 \mathrm{~mL}$ HBSS) were injected subcutaneously into C57BL/ 6 mice. To confirm the presence of circulating PD-L1 in TC-1 tumor-bearing mice, PLGA (PD-L1 siRNA)-NPs ( $5 \mu \mathrm{g}$ of PD-L1 siRNA) were intravenously injected into the mice twice in a week. On day 7, serum and tumor tissues were collected and analyzed for PD-L1 using ELISA.

\section{Migration assay of tumor cells}

Prior to the TC- 1 cell migration assay, TC- 1 cells $\left(3 \times 10^{5}\right)$ were seeded into 6 -well plates and incubated overnight. After making a scratch, the TC-1 cells were further incubated with PLGA (PD-L1 siRNA+PD-1 siRNA)-NPs (2 $\mu \mathrm{g}$ of siRNA) or anti-PD-L1+anti-PD-1 (2 $\mu \mathrm{g}$ of antibody). After 24 hours, the tumor cell migration was confirmed, and the level of PD-1, PD-L1, MMP-9, and PCNA in the tumor cells were confirmed using western blot analysis.

\section{Proliferation assay for $\mathrm{CD8}^{+} \mathrm{T}$ cells}

Prior to the $\mathrm{CD}^{+}$Tcell proliferation assay, $\mathrm{CD} 8^{+} \mathrm{T}$ cells and TC-1 cells were stimulated to induce PD-1 and PD-L1 expression, following which PD-1 and PD-L1 were silenced using PLGA (PD-L1 siRNA+PD-1 siRNA)-NPs. $\mathrm{CD}^{+} \mathrm{T}$ cells were labeled with CFSE, and then seeded into 48 -well plates at a cell density of $1 \times 10^{6}$ cells/well. TC-1 cells were added to the CFSE-labeled CD8 ${ }^{+} \mathrm{T}$ cells at various E:T ratios (where effector: $\mathrm{CD} 8^{+} \mathrm{T}$ cell and target: TC-1 cells; 1:1, 1:5, 1:10, 1:50, and 1:100). After 48 hours of incubation, the proliferation of $\mathrm{CD}^{+} \mathrm{T}$ cells was examined using flow cytometry. ${ }^{25}$

\section{Activation of $\mathrm{CDB}^{+} \mathrm{T}$ cells}

To determine the functional effect of PD-L1 secreted from TC-1 against $\mathrm{CD} 8^{+} \mathrm{T}$ cells, TC-1 cells were stimulated with IFN- $\gamma$ to express PD-L1. Next, $2 \mu \mathrm{g}$ of anti-PD-L1 or $2 \mu \mathrm{g}$ of PLGA (PD-L1 siRNA)-NPs was added to the cells and they were incubated for 3 days. At the end of the incubation, the TCM was collected and centrifuged at $1500 \mathrm{rpm}$ 
for $3 \mathrm{~min}$. The supernatant was collected and stored at $-70^{\circ} \mathrm{C}$. CD $8^{+} \mathrm{T}$ cells $\left(1 \times 10^{6}\right.$ cells $/$ well $)$ stimulated using anti-CD3 and anti-CD28 were seeded into 48-well plates. RPMI 1640 medium alone was used as a negative control, to which TCM was added. After 24 hours incubation, IFN- $\gamma$ and IL-2 secreted from $\mathrm{CD} 8^{+} \mathrm{T}$ cells were measured using ELISA, and the expression levels of AKT and p-AKT in $\mathrm{CD}^{+} \mathrm{T}$ cells were measured using western blot analysis. In addition, the activation of $\mathrm{CD}^{+} \mathrm{T}$ cells was determined in terms of the expression levels of granzyme B and CD107a in $\mathrm{CD}^{+} \mathrm{T}$ cells, which were assessed using flow cytometry.

\section{Antitumor efficacy of PLGA (PD-L1 siRNA+PD-1 siRNA)-NPs}

Prior to measuring the therapeutic efficacy, we assessed the biodistribution of PLGA (Cy5)-NPs after injection into TC-1 tumor-bearing mice. To generate tumors, TC-1 cells $\left(1 \times 10^{6}\right.$ cells $/ 0.1 \mathrm{~mL}$ HBSS $)$ were subcutaneously injected into C57BL/6 mice. After growing the tumor tissue, PLGA (Cy5)-NPs were intravenously injected into the mice ( $n=3$ /group). Cy5 is a fluorescent, which was used as a model drug. After 24 hours, biodistribution of PLGA (Cy5)-NP into tumor-bearing mice was monitored using in vivo imaging system (Perkin Elmer, Waltham, Massachusetts, USA) at the appropriate wavelength $(\lambda \mathrm{ex}=680 \mathrm{~nm}$ and $\lambda \mathrm{em}=740 \mathrm{~nm})$. The emitted signals were collected using a time-correlated single-photon counting system software (Living image 4.5.5).

We next evaluated the therapeutic efficacy of PLGA-NPs in TC-1 and EG7 tumor-bearing mice. To generate tumors, TC-1 cells $\left(1 \times 10^{6}\right.$ cells $/ 0.1 \mathrm{~mL}$ HBSS $)$ or EG7 cells $\left(1 \times 10^{6}\right.$ cells $/ 0.1 \mathrm{~mL}$ HBSS) were subcutaneously injected into C57BL $/ 6$ mice. The mice ( $\mathrm{n}=5 /$ group) were monitored daily for adverse effects of treatment and euthanized when the control group seemed moribund. The PLGA (E7+poly I:C)-NP or PLGA (OVA+poly I:C)-NP vaccine used in the previous study was injected to induce a tumor antigen-specific immune response. ${ }^{22}$ The PLGA (E7+poly I:C)-NP (E7 and poly I:C; $0.3 \mathrm{mg} / \mathrm{kg}$ of each) or PLGA (OVA+poly I:C)-NP (OVA and poly I:C; $5 \mathrm{mg} / \mathrm{kg}$ of each) vaccine was administered once per week for 2 weeks by means of subcutaneous injection. Anti-PD-1, anti-PD-L1, anti-PD-1+anti-PD-L1, PLGA (PD-L1 siRNA)-NPs, PLGA (PD-1 siRNA)-NPs, and PLGA (PD-L1 siRNA+PD-1 siRNA)-NPs were then administered twice per week for 4 weeks by means of intravenous injection at a dose of $200 \mu \mathrm{g} / \mathrm{kg}$ of each antibody or siRNA. Tumor volume and survival of the mice were recorded. The tumor volume was measured using calipers, and the volume was calculated using the following formula ${ }^{26}$ :

$$
\text { Tumor volume }\left(\mathrm{mm}^{3}\right)=\text { length }(\text { width })^{2} / 2
$$

Tumor volume, tumor weight in the mice, and images of tumor-bearing mice were recorded. The investigators who performed the necropsies, tumor collection, and tissue processing were blinded to the treatment groups. Tissue specimens were fixed with either $4 \%$ paraformaldehyde or optimum cutting temperature compound.

\section{Immunohistochemical staining}

Procedures for immunohistochemical analysis of PD-L1 (anti-PD-L1) and PD-1 (anti-PD-1) expression, CD8 ${ }^{+}$ Tcell population (anti-CD8), and cell proliferation (antiKi67) were performed. ${ }^{22} 27$ All of these analyses were recorded in five random fields per slide. The bar graph indicates the percentage of positive (brown)/total tumor cells (blue) in the same tissue area. In addition, TUNEL assay was performed to determine cell apoptosis. ${ }^{22}$ Apoptotic cells were quantified by counting the number of apoptotic cells in five random fields of each slide at $\times 400$ magnification.

\section{Biochemical toxicity of PLGA (PD-L1 siRNA+PD-1 siRNA)-NPs} Female C57BL/6 mice (5-6 weeks old, 20 g) were grouped as follows ( $\mathrm{n}=3$ /group): (1) control and (2) PLGA (PD-L1 siRNA+PD-1 siRNA)-NPs. Mice in the PLGA (PD-L1 siRNA+PD-1 siRNA)-NPs group were intravenously injected with a single treatment of the same therapeutic dose. To determine the biochemical toxicity of the PLGA (PD-L1 siRNA+PD-1 siRNA)-NPs, the levels of aminotransferase (AST), alanine aminotransferase (ALT), and blood urea nitrogen (BUN) were analyzed using diagnostic kits (Roche, Basel, Switzerland). Blood samples were collected from the mice through the retroorbital sinus on days 1 and 7 after injection of PLGA (PD-L1 siRNA+PD-1 siRNA)-NPs. Serum was obtained from the blood by means of centrifugation at $3000 \mathrm{rpm}$, $4^{\circ} \mathrm{C}$ for $10 \mathrm{~min}$.

\section{Statistical analysis}

Differences in continuous variables were analyzed using Student's t-test, for comparison between two groups, while analysis of variance was performed to assess differences among multiple groups. The Mann-Whitney rank-sum test was performed for values that were not normally distributed. The Statistical Package for the Social Sciences version 22 was used for all calculations. Differences were considered statistically significant at $\mathrm{p}<0.05$.

\section{RESULTS \\ Characteristics of PLGA (PD-L1 siRNA+PD-1 siRNA)-NPs}

In this study, we prepared PLGA-NPs incorporating an siRNA system for target gene silencing of immunosuppressive PD-L1 and PD-1. This siRNA-based immune checkpoint silencing system could fundamentally inhibit the secretion of PD-L1 from tumor cells into the tumor microenvironment, leading to an increased immune response compared with antibody-based blockades (figure 1A). We first determined the physical properties of the PLGA (PD-L1 siRNA+PD-1 siRNA)-NPs. Mean particle size and surface charge of PLGA-NPs were around $231 \pm 5.53 \mathrm{~nm}$ and $-7.62 \pm 0.33 \mathrm{mV}$, respectively. The loading efficiency of both PD-1 siRNA and PD-L1 siRNA into PLGA-NPs was up to $65.1 \%$, while the polydispersity index was $0.15 \pm 0.13$ (figure 1B). Representative histograms of the size distribution and spherical morphologies, as observed using 


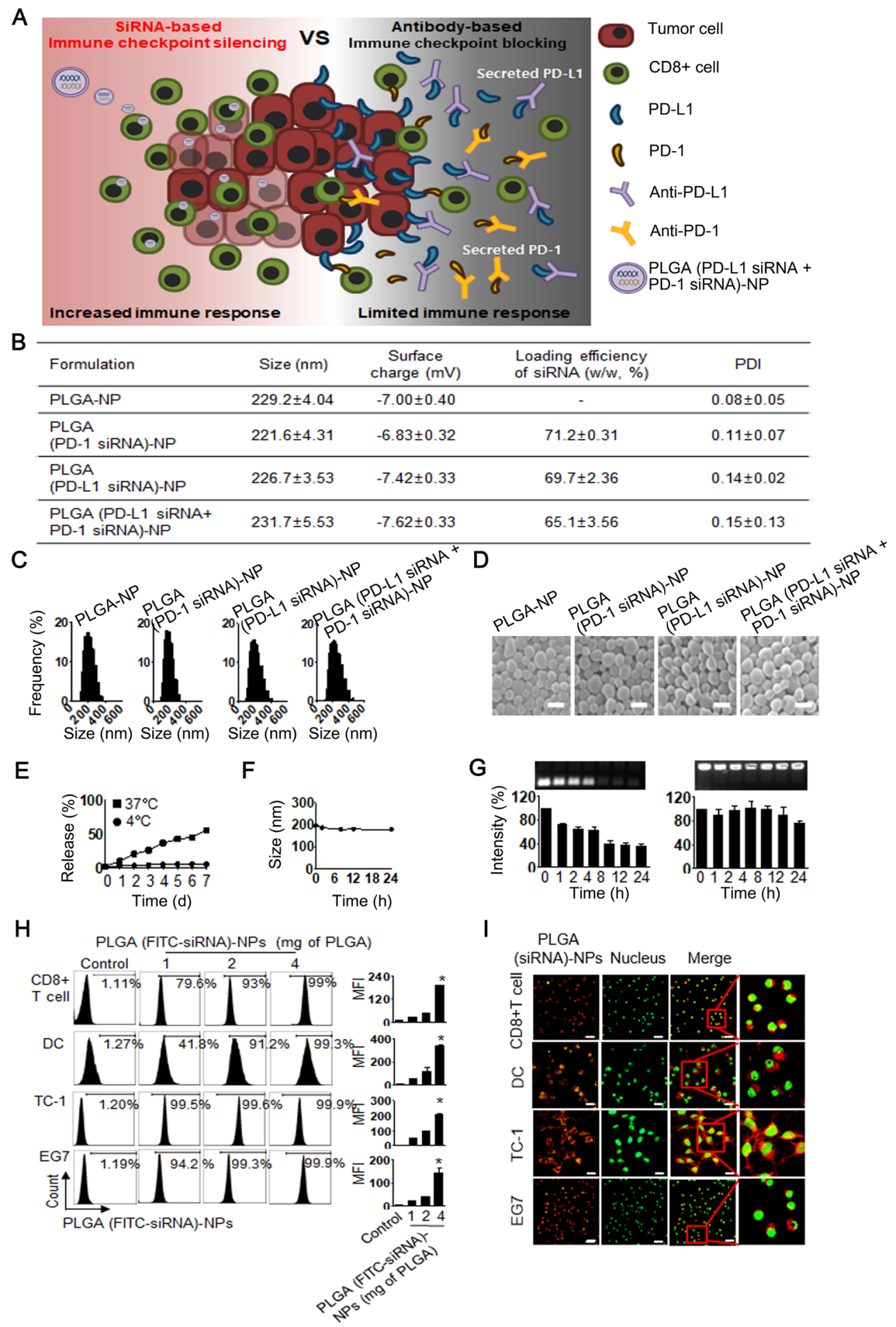

Figure 1 Physical properties of poly(lactic-co-glycolic acid) (PLGA) (small interfering RNA (siRNA))-nanoparticles (NPs). (A) A conceptual scheme of this study, which aimed at immune checkpoint silencing using a siRNA-based nanoparticle platform. (B) Physical characteristics of PLGA (siRNA)-NPs. (C) Size distribution and (D) morphology of PLGA (siRNA)-NPs (scale bar: $200 \mathrm{~nm}$ ). (E) Release of siRNA from PLGA (siRNA)-NPs in phosphate-buffered saline at $4^{\circ} \mathrm{C}$ or $37^{\circ} \mathrm{C}$. (F) Stability of PLGA (siRNA)-NPs in $50 \%$ serum at $37^{\circ} \mathrm{C}$. (G) Electrophoresis of PLGA (siRNA)-NPs in $50 \%$ serum. Intracellular delivery efficiency of PLGA (siRNA)-NPs in CD8 ${ }^{+}$T cells, dendritic cells (DCs), TC-1, and EG7 cells. The cells were incubated for 30 min at $37^{\circ} \mathrm{C}$. (H) Flow cytometry analysis for PLGA (fluorescein isothiocyanate (FITC)-siRNA)-NPs. (I) Confocal microscopic images for PLGA (rhodamine-siRNA)-NPs. Red color indicates rhodamine-siRNA, while green indicates the nuclei of the cells (scale bar: $20 \mu \mathrm{m}$ ). Error bars represent SEM. ${ }^{*} \mathrm{P}<0.001$. 
SEM and a particle size analyzer, are given in figure 1C,D. The release of siRNA from PLGA (siRNA)-NPs showed a weak increase at $4^{\circ} \mathrm{C}$, however, siRNA showed sustained release of up to $56 \%$ for 7 days at $37^{\circ} \mathrm{C}$ (figure $1 \mathrm{E}$ ). Moreover, the size of PLGA (siRNA)-NP was maintained in $50 \%$ serum solution at $37^{\circ} \mathrm{C}$, indicating that PLGA (siRNA)-NP was stable in serum (figure $1 \mathrm{~F}$ ). Next, we determined the stability of siRNA in a 50\% serum solution using electrophoresis. Although naked siRNA degraded with incubation time, encapsulation of the siRNA with PLGA (siRNA)-NP protected against degradation (figure 1G). In addition, the physical properties of PLGA (OVA+poly I:C)-NPs and PLGA (E7+poly I:C)-NPs used in this study as therapeutic NP-based vaccines are shown in online supplemental figure S1.

\section{Intracellular delivery of PLGA (siRNA)-NPs}

We next assessed the intracellular delivery of PLGA-NPs incorporating FITC-labeled siRNA using flow cytometry and confocal microscopy (figure $1 \mathrm{H}, \mathrm{I}$ ). The intracellular delivery efficiency of PLGA (FITC-siRNA)-NPs increased in a dose-dependent manner in immune cells $\left(\mathrm{CD}^{+} \mathrm{T}\right.$ cells and DCs) and tumor cells (TC-1 and EG7) $(\mathrm{p}<0.001$, figure $1 \mathrm{H}$ ). We observed the intracellular delivery of PLGA (rhodamine-siRNA)-NPs in various cells to confirm siRNA delivery using confocal microscopy, resulting that siRNA showed effective intracellular delivery in both immune cells and tumor cells (figure 1I). In addition, intracellular delivery of PLGA (Cy5)-NPs without siRNA incorporation was confirmed (online supplemental figure S2).

\section{Immune checkpoint silencing}

We performed western blot analysis and flow cytometry analysis to determine the gene silencing effect of PD-1 and PD-L1 in various cells. Prior to confirming immune checkpoint silencing, we induced $\mathrm{CD} 8^{+}$Tcell activation using both anti-CD3 and anti-CD28 to increase PD-1 expression on the cell surface (online supplemental figure S3A). In addition, we induced PD-L1 expression on the surface of tumor cells by means of IFN- $\gamma$ stimulation (online supplemental figure S3B). PLGA (PD-L1 siRNA+PD-1 siRNA)-NPs significantly inhibited PD-1 expression in $\mathrm{CD}^{+} \mathrm{T}$ cells $(\mathrm{p}<0.001$, figure $2 \mathrm{~A})$ as well as PD-L1 expression in DCs $(\mathrm{p}<0.001), \mathrm{TC}-1(\mathrm{p}<0.001)$, and EG7 $(\mathrm{p}<0.01)$ cells compared with those in the control (figure 2B-D).

\section{Migration and cell growth after immune checkpoint silencing of tumor cells}

In this study, we hypothesized that antibody-based approaches might be less effective than siRNA approaches because antibody blockades can bind to the secreted PD-L1, which leads to the suppression of therapeutic outcomes (figure 3A). Based on our study conceptualization, we observed the secretion of PD-L1 from tumor cells and anticipated that the use of siRNA might prevent PD-L1 secretion. PD-L1 expression was found in the TCM from untreated cells, whereas weak PD-L1 expression was found in both TC-1 cells and the TCM after treatment with PLGA (PD-L1 siRNA)-NPs ( $<<0.001$, figure 3B). This result clearly indicates that PD-L1 silencing by PD-L1 siRNA can prevent the secretion of PD-L1 from tumor cells. Moreover, to determine the secretion of PD-L1 into the bloodstream, we analyzed PD-L1 circulation after PLGA (PD-L1 siRNA)-NP treatment. When PLGA (PD-L1 siRNA)-NPs were injected into TC-1 tumor-bearing mice by means of intravenous injection, there was a significant decrease in the PD-L1 circulation in the bloodstream, as compared with that in the control and anti-PD-L1-treated groups $(\mathrm{p}<0.05$, figure $3 \mathrm{C})$.

Remarkably, recent studies have found intrinsic PD-1 expression in tumor cells, and PD-1 additionally induces PD-L1 expression in tumor cells through cross-reactive stimulation in the tumor microenvironment, which promotes tumor cell growth and migration. ${ }^{28}$ Therefore, we confirmed cell growth and migration after silencing of both PD-1 and PD-L1 in TC-1 tumor cells. Although antiPD-1+anti-PD-L1 treatment showed weak inhibition, treatment with PLGA (PD-L1 siRNA+PD-1 siRNA)-NPs showed $53 \%$ inhibition of cell growth and migration $(\mathrm{p}<0.001$, figure 3D). Additionally, PLGA (PD-L1 siRNA+PD-1 siRNA)-NP treatment led to a significant decrease in MMP-9 and PCNA expression, as compared with that on control ( $p<0.001$, figure $3 \mathrm{E})$. These results indicated that dual silencing of PD-1 and PD-L1 in tumor cells is more effective in inhibiting cell growth and migration.

\section{Proliferation and activation of $\mathrm{CDB}^{+} \mathrm{T}$ cells}

We next confirmed whether the proliferation of $\mathrm{CD}^{+}$ $\mathrm{T}$ cells increased after PD-1 and PD-L1 silencing. After stimulating $\mathrm{CD}^{+} \mathrm{T}$ cells using anti-CD3 and anti-CD28, we silenced PD-1 using PLGA (PD-L1 siRNA+PD-1 siRNA)-NPs. Additionally, TC-1 cells were stimulated with IFN- $\gamma$ to increase PD-L1 expression, following which the PD-L1 in TC-1 cells was silenced using PLGA (PD-L1 siRNA+PD-1 siRNA)-NPs. The PLGA (PD-L1 siRNA+PD-1 siRNA)-NP treatment group showed significantly increased proliferation of $\mathrm{CD}^{+} \mathrm{T}$ cells with an increasing E:T ratio (E: effector $\mathrm{CD}^{+} \mathrm{T}$ cells, T: target TC-1 cells) compared with that in the control group $(p<0.001$, figure $4 \mathrm{~A})$.

PD-L1 secreted from tumor cells into the tumor microenvironment has been found to decrease $\mathrm{CD}^{+} \mathrm{T}$ cell activation. ${ }^{29}$ Therefore, we assessed whether secreted PD-L1 decreased CD8 ${ }^{+}$Tcell activation by measuring p-AKT expression because p-AKT is highly associated with $\mathrm{CD}^{+}{ }^{\mathrm{T}}$ cell activation and proliferation. ${ }^{30}$ The TCM was prepared by isolating TC-1 culture media after PD-L1 silencing using PLGA (PD-L1 siRNA)-NPs. Subsequently, $\mathrm{CD}^{+} \mathrm{T}$ cells were cultured in TCM for 24 hours. There was a significant increase in p-AKT expression in $\mathrm{CD} 8^{+} \mathrm{T}$ cells cultured in PD-L1-silenced TCM as compared with that in control and anti-PD-L1-treated groups $(p<0.05)$, indicating that activation of $\mathrm{CD} 8^{+} \mathrm{T}$ cells may be induced by the increasing p-AKT expression caused by inhibition of PD-L1 secretion from TC-1 tumor cells (figure 4B). 


\section{A; CD8+ T cell}
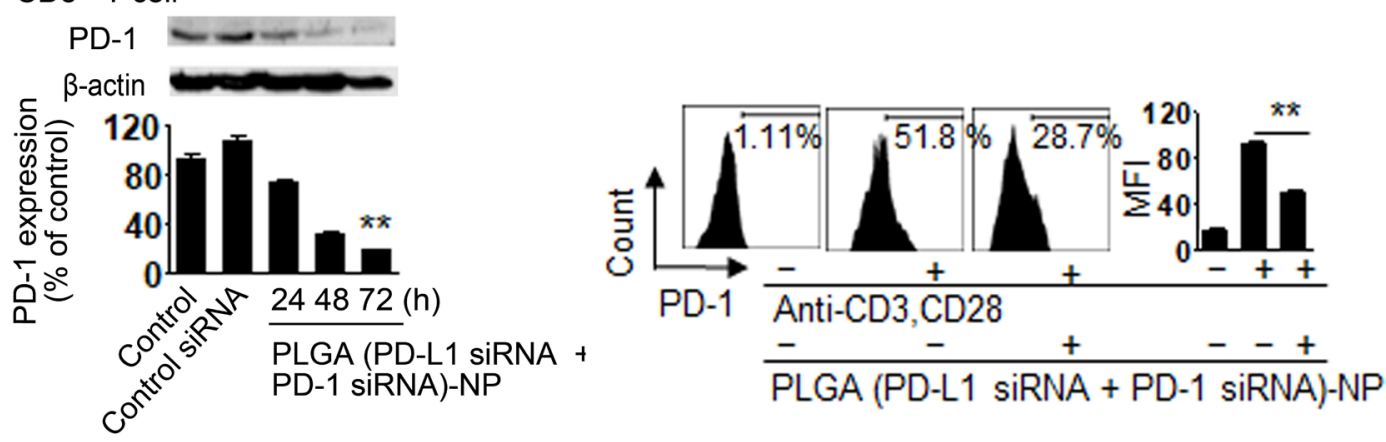

B; DC
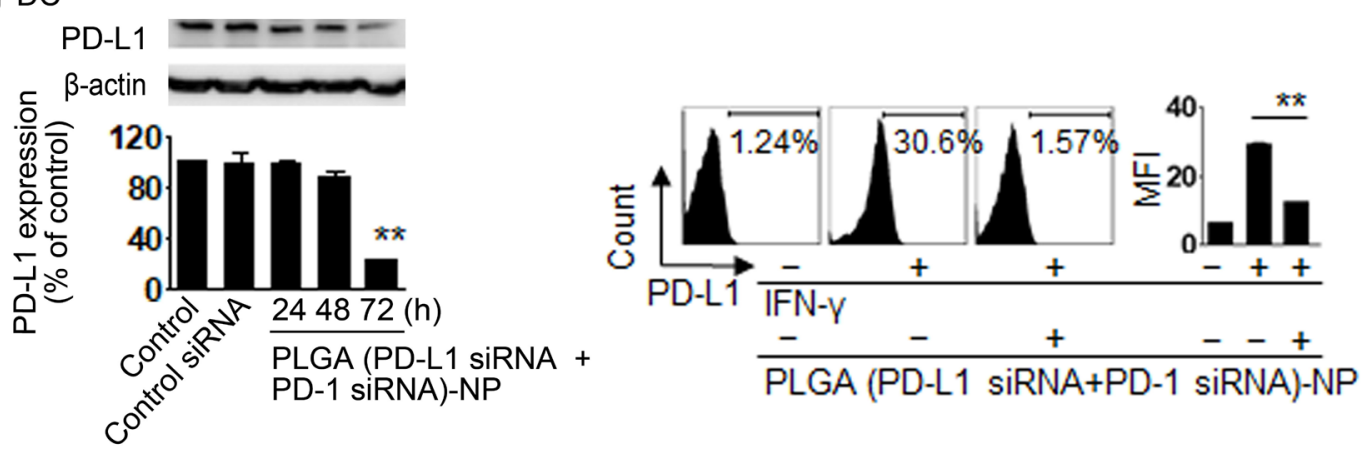

C; TC-1
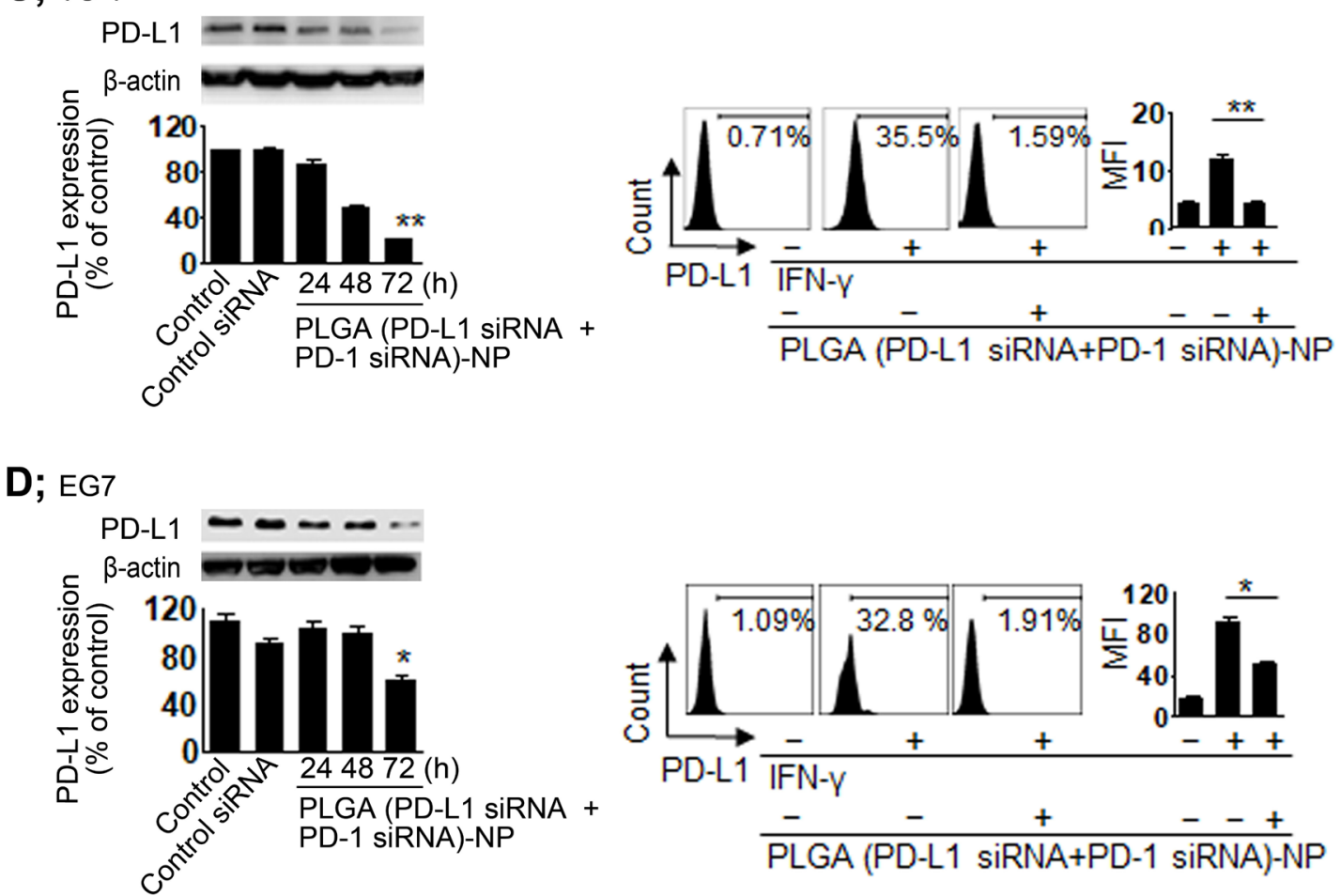

Figure 2 Programmed cell death 1 (PD-1) and programmed death ligand 1 (PD-L1) silencing using poly(lactic-co-glycolic acid) (PLGA) (small interfering RNA (siRNA))-nanoparticles (NPs). (A) PD-1 silencing in CD8 ${ }^{+}$T cells was assessed using western blot analysis and flow cytometry. CD8 ${ }^{+}$T cells were stimulated with anti-CD3 and anti-CD28 for 24 hours to increase PD-1 expression and then treated with PLGA (PD-L1 siRNA+PD-1 siRNA)-NPs. PD-L1 silencing in (B) dentritic cells (DCs), (C) TC-1 cells, and (D) EG7 cells was assessed using western blot analysis and flow cytometry. The cells were stimulated with interferon (IFN)- $\gamma$ for 24 hours to increase PD-L1 expression and then treated with PLGA (PD-L1 siRNA+PD-1 siRNA)-NPs. Error bars represent the SEM. ${ }^{*} P<0.01$ and ${ }^{* *} p<0.001$. 
A

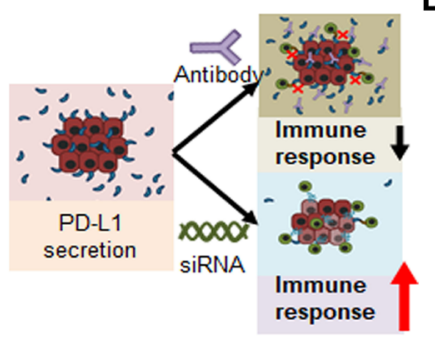

B
C

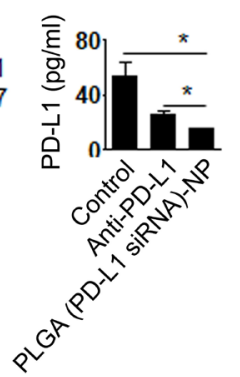

D
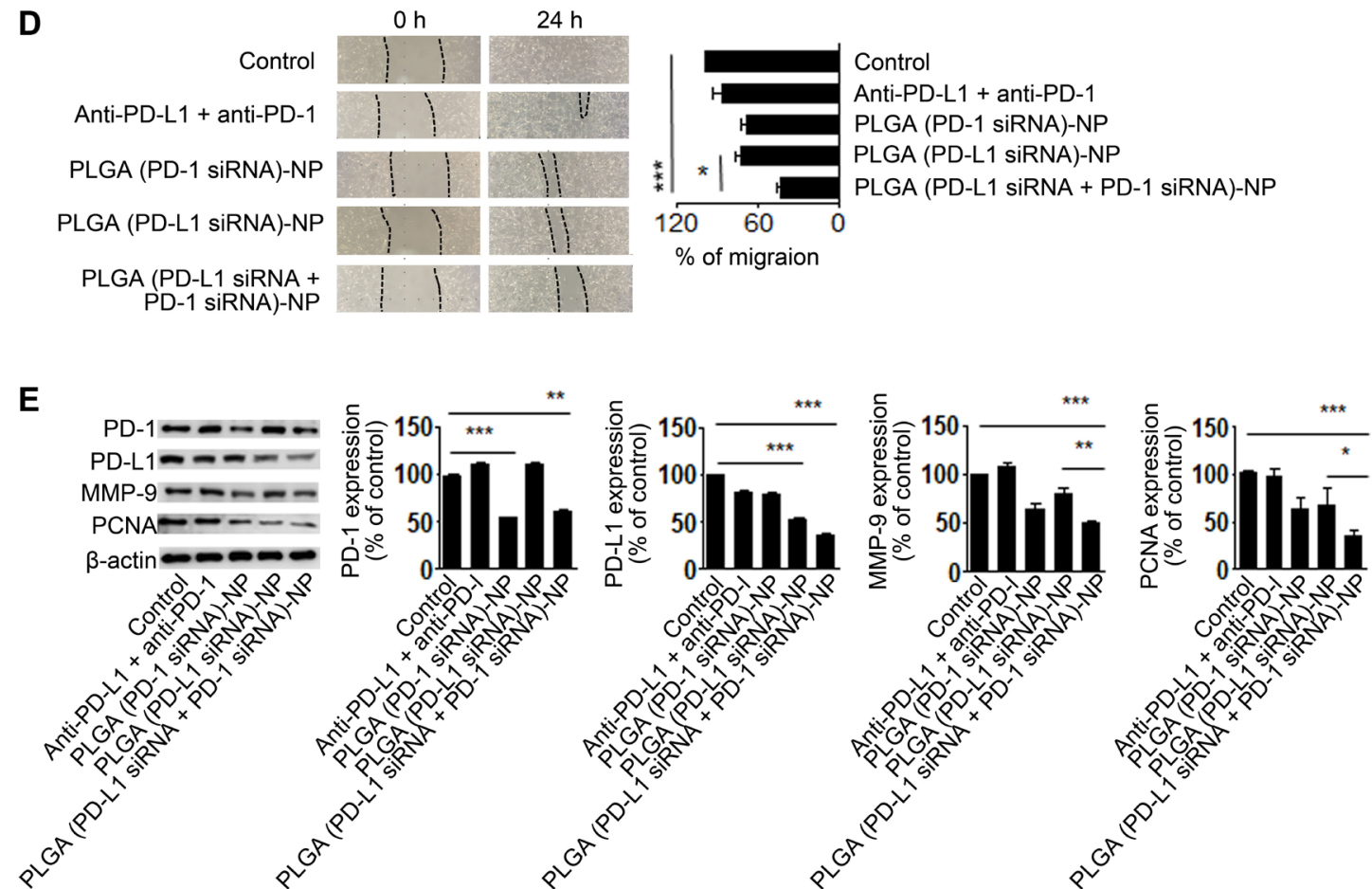

Figure 3 Migration and cell growth after immune checkpoint silencing. (A) An illustration of the strategy for small interfering RNA (siRNA)-based immune checkpoint silencing. (B) Secreted programmed death ligand 1 (PD-L1) in the tumor-conditioned media (TCM) was determined using western blot analysis. Tumor cells were stimulated with interferon (IFN)- $\gamma$ for 24 hours to increase PD-L1 expression on their surface membrane. The tumor cells were incubated with poly(lactic-co-glycolic acid) (PLGA) (PD-L1 siRNA)-NPs for 72 hours. (C) Seven days after injection of PLGA (PD-L1 siRNA)-nanoparticles (NPs) into TC-1 tumor-bearing mice, the mice were sacrificed, and blood was collected from them to obtain serum. PD-L1 levels in the serum were evaluated using ELISA. (D) TC-1 cell growth and migration after PLGA (PD-L1 siRNA+programmed cell death 1 (PD-1) siRNA)-NPs treatment for 24 hours. (E) Cell growth and migration analysis were assessed using western blot analysis. Error bars represent the SEM. ${ }^{*} \mathrm{P}<0.05,{ }^{* *} \mathrm{p}<0.01$, and ${ }^{* *} \mathrm{p}<0.001$.

Moreover, under the same conditions, we measured levels of the inflammatory cytokines IL-2, IFN- $\gamma$, granzyme $\mathrm{B}$, and degranulation marker $\mathrm{CD} 107 \mathrm{a}$ as these serve as $\mathrm{CD} 8^{+} \mathrm{T}$ cell activation biomarkers. There was a significant increase $(\mathrm{p}<0.001)$ in the levels of IFN- $\gamma$, IL-2, granzyme $\mathrm{B}$, and $\mathrm{CD} 107 \mathrm{a}$ in $\mathrm{CD} 8^{+} \mathrm{T}$ cells (figure $4 \mathrm{C}-\mathrm{D}$ ), indicating that inhibition of PD-L1 secretion from tumor cells contributed to $\mathrm{CD}^{+}$T cell activation and could help restore $\mathrm{CD}^{+} \mathrm{T}$ cell proliferation.

\section{Therapeutic efficacy of PLGA (PD-L1 siRNA+PD-1 siRNA)-NPs} Prior to assessing therapeutic efficacy, we observed the delivery efficiency of PLGA (Cy5)-NPs to the tumor microenvironment on intravenous injection into tumorbearing mice. The PLGA (Cy5)-NPs showed effective accumulation in the tumor microenvironment (online supplemental figure S4). Based on the results of delivery efficiency, we determined the potential therapeutic efficacy of PLGA (PD-L1 siRNA+PD-1 siRNA)-NPs using the TC-1 tumor model. TC-1 cells were derived from primary lung epithelial cells of C57BL/6 mice and expressed HPV16-E6 and HPV16-E7. ${ }^{22}$ In addition, to extend our concept, we used E7 peptide-incorporated PLGA (E7+poly I:C)-NPs as a therapeutic vaccine to induce an E7-specific $\mathrm{CD}^{+} \mathrm{T}$ cell immune response. ${ }^{31}{ }^{32}$ Vaccination with PLGA (E7+poly I:C)-NPs led to an increased antigenspecific immune response, as has been reported previously. ${ }^{22}$ Seven days after subcutaneous injection of TC-1 tumor cells into C57BL/ 6 mice, PLGA (E7+poly I:C)-NPs 
A

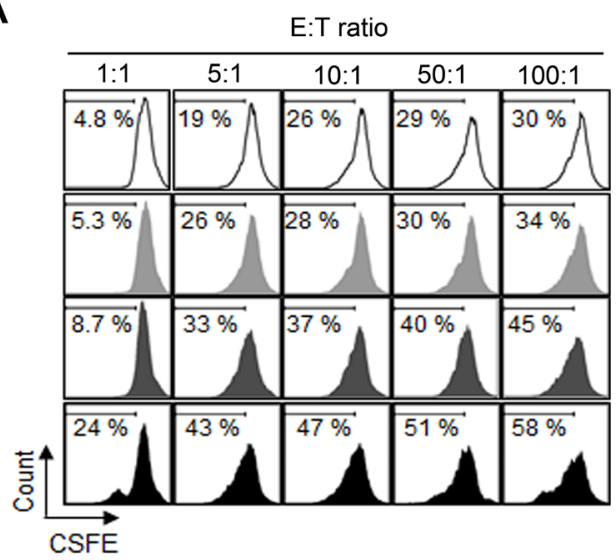

$\square$ Control

$\square$ TC-1 cells *

$\square$ CD8+ T cells *

- TC-1 and CD8+ T cells *

* Treated with PLGA (PD-L1 siRNA + PD-1 siRNA)-NP

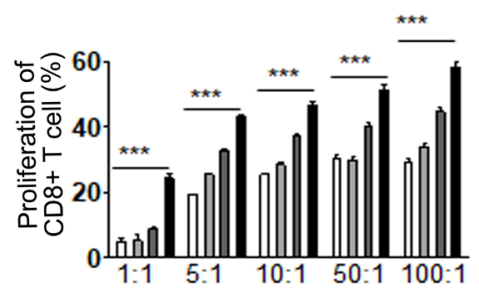

B

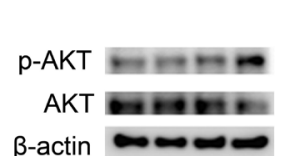

$\beta$-actin

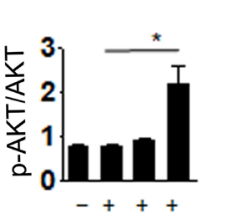

C

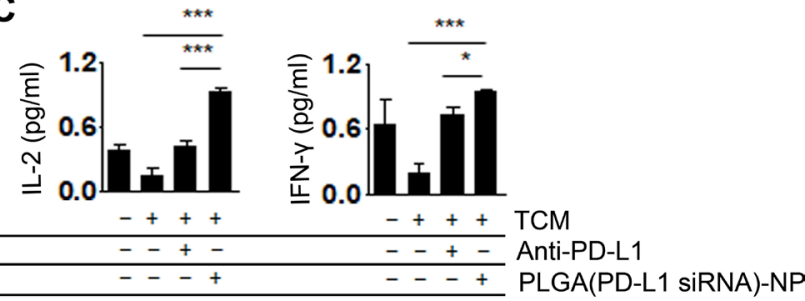

D
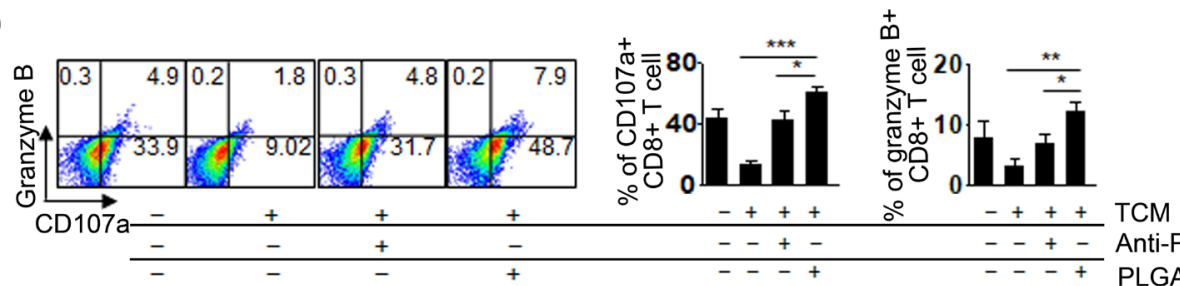

Anti-PD-L1

PLGA(PD-L1 siRNA)-NP

Figure 4 Proliferation and activation of $\mathrm{CD} 8^{+} \mathrm{T}$ cells. (A) Quantitative analysis of proliferating $\mathrm{CD} 8^{+} \mathrm{T}$ cells was carried out using flow cytometry. CD8 ${ }^{+} \mathrm{T}$ cells were isolated from splenocytes and labeled with carboxyfluorescein diacetate succinimidyl ester (CFSE). The CD8 ${ }^{+} \mathrm{T}$ cells were stimulated with anti-CD3 and anti-CD28, and then co-cultured with TC-1 cells for 48 hours (effecter: $\mathrm{CD}^{+}$T cell, target: TC-1). (B) Activation of $\mathrm{CD}^{+} \mathrm{T}$ cells in the tumor-conditioned media (TCM) was assessed using western blot analysis. TCM was isolated from TC-1-cultured media after programmed death ligand 1 (PD-L1)-silencing. (C) Proinflammatory cytokines in the TCM from CD8 ${ }^{+} \mathrm{T}$ cells were measured using ELISA. (D) Granzyme B and CD107a in the TCM from $C D 8^{+} T$ cells were measured using flow cytometry. Error bars represent the $S E M .{ }^{*} \mathrm{P}<0.05,{ }^{* *} \mathrm{p}<0.01$, and ${ }^{* \star *} \mathrm{p}<0.001$.

were subcutaneously injected into the mice twice at an interval of 1 week. The mice were then randomly allocated to the following groups ( $\mathrm{n}=5 \mathrm{mice} /$ group): (1) negative control (without vaccination), (2) positive control (with vaccination), (3) anti-PD-L1 with vaccination, (4) anti-PD-1 with vaccination, (5) anti-PD-L1+antiPD-1 with vaccination, (6) PLGA (PD-L1 siRNA)-NPs with vaccination, (7) PLGA (PD-1 siRNA)-NPs with vaccination and (8) PLGA (PD-L1 siRNA+PD-1 siRNA)-NPs with vaccination. Antibodies $(200 \mu \mathrm{g} / \mathrm{kg})$ and siRNA (200 $\mu \mathrm{g} / \mathrm{kg}$ ) were intravenously injected into the TC-1 tumorbearing mice twice in a week for 4 weeks (figure 5A). The PLGA (PD-L1 siRNA+PD-1 siRNA)-NPs with vaccination group showed significant inhibition of tumor growth as compared with the positive control with vaccination $(84 \%$ decrease, $\mathrm{p}<0.01)$ and anti-PD-L1+anti-PD-1 with vaccination groups $(74 \%$ decrease, $\mathrm{p}<0.01$, figure $5 \mathrm{~B})$. Notably, there was a significant reduced in tumor weight in the PLGA (PD-L1 siRNA+PD-1 siRNA)-NPs with vaccination group as compared with that in the positive control with vaccination $(83 \%$ decrease, $\mathrm{p}<0.001)$ and anti-PDL1+anti-PD-1 with vaccination groups $(78 \%$ decrease, $\mathrm{p}<0.001$ ) (figure 5C).

To determine the potential therapeutic mechanisms underlying the efficacy of PLGA (PD-L1 siRNA+PD-1 siRNA)-NPs in tumor tissues, we examined the tumors for PD-L1 (anti-PD-L1) and PD-1 (anti-PD-1) expression, infiltration of $\mathrm{CD}^{+} \mathrm{T}$ cells (anti-CD8), cell proliferation (anti-Ki67), and apoptosis (TUNEL assay) (figure 5D). PLGA (PD-L1 siRNA+PD-1 siRNA)-NP treatment significantly inhibited PD-L1 and PD-1 expression $(\mathrm{p}<0.001)$, increased $\mathrm{CD}^{+}$T cell infiltration $(\mathrm{p}<0.01)$, reduced cell proliferation $(\mathrm{p}<0.001)$, and increased apoptosis $(\mathrm{p}<0.05)$ as compared with those in the other groups.

To establish that the therapeutic effects of PLGA (PD-L1 siRNA+PD-1 siRNA)-NPs are not unique to just one target tumor, we used an additional system, OVAexpressing EG7-OVA (EL4 cell line transfected with the gene encoding for OVA) lymphoma cells. ${ }^{22}$ Seven days after subcutaneous injection of EG7 cells into C57BL/6 
A

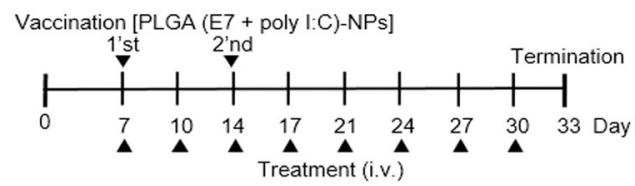

(1); Control without vaccination

(2); ○ Control with vaccination

(3); Anti-PD-L1 with vaccination

(4); Anti-PD-1 with vaccination

(5); $\mathbf{v}$ Anti-PD-L1+PD-1 with vaccination

(6); $\square$ PLGA (PD-L1 siRNA)-NP with vaccination

(7); $\triangle$ PLGA (PD-1 siRNA)-NP with vaccination

(8); $\nabla$ PLGA (PD-L1 siRNA + PD-1 siRNA)-NP with vaccination
B

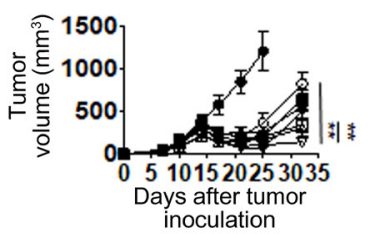

C

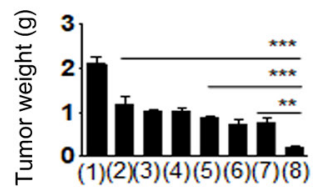

D
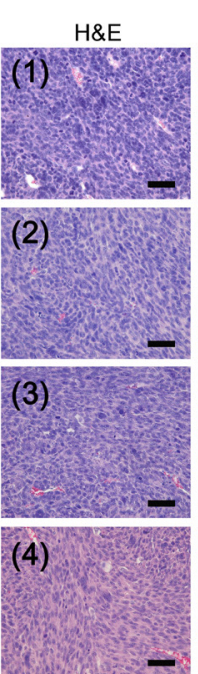

(5)
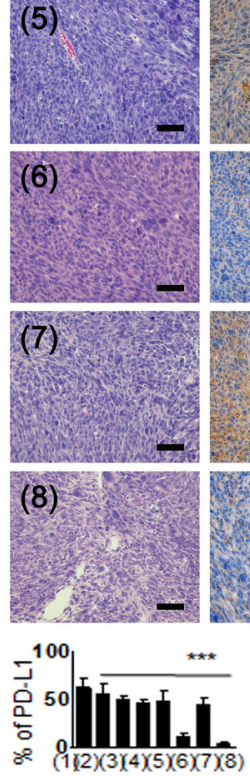

PD-L1
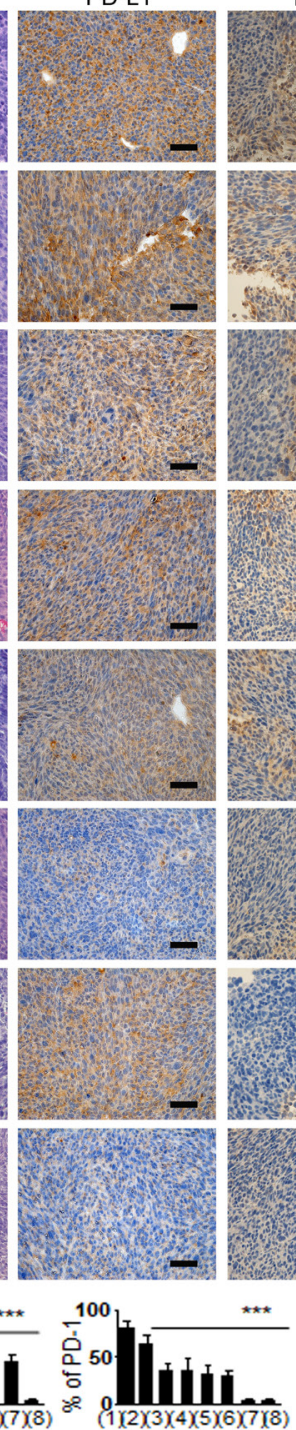

PD-1
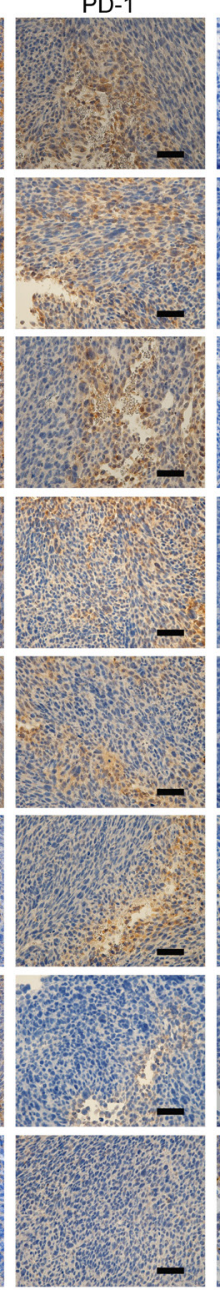

*** $\quad 30 \quad 100$
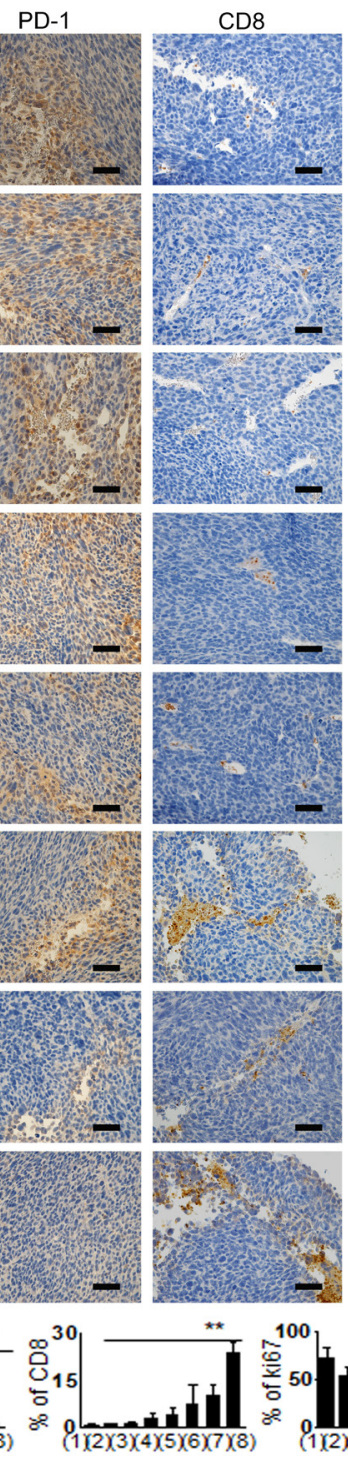
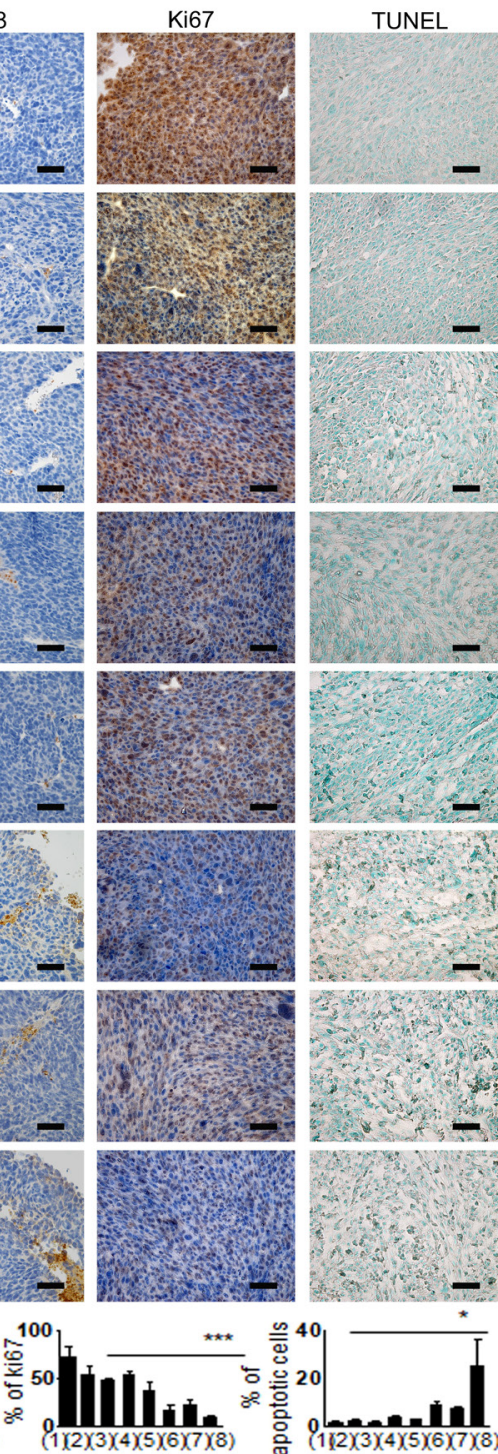

Figure 5 Therapeutic efficacy of poly(lactic-co-glycolic acid) (PLGA) (small interfering RNA (siRNA))-nanoparticles (NPs) against TC-1 tumor-bearing C57BL/6 mouse model. Treatment began 1 week after subcutaneous injection of TC-1 cells into the mice. PLGA (E7+poly I:C)-NPs were subcutaneously injected as a therapeutic vaccine, once per week for 2 weeks. The PLGA (programmed death ligand 1 (PD-L1) siRNA+programmed cell death 1 (PD-1) siRNA)-NPs with vaccination (200 $\mu \mathrm{g} / \mathrm{kg}$ of siRNA or antibody) was intravenously injected twice per week for 4 weeks. (A) Experimental schedule for tumor therapy. (B) Tumor volume and (C) tumor weight. (D) Immunohistochemical analysis of TC-1 tumor tissues for PD-L1 (anti-PD-L1) and PD-1 (antiPD-1) expression, infiltration of CD8 ${ }^{+} \mathrm{T}$ cells (anti-CD8), cell proliferation (anti-Ki67), and apoptosis (Terminal deoxynucleotidyl transferase dUTP nick end labeling (TUNEL) assay) (scale bar: $50 \mu \mathrm{m}$ ). Error bars represent the SEM. ${ }^{*} \mathrm{P}<0.05,{ }^{* \star} \mathrm{p}<0.01$, and ${ }^{* * *} \mathrm{p}<0.001$. 
mice twice in a week, vaccination with PLGA (OVA+poly I:C)-NPs was performed via the subcutaneous route. The mice were then randomly allocated to the following groups ( $\mathrm{n}=5$ mice/group): (1) negative control (without vaccination), (2) positive control (with vaccination), (3) anti-PD-L1 with vaccination, (4) anti-PD-1 with vaccination, (5) anti-PD-L1+anti-PD-1 with vaccination, (6) PLGA (PD-L1 siRNA)-NPs with vaccination, (7) PLGA (PD-1 siRNA)-NPs with vaccination, and (8) PLGA (PD-L1 siRNA+PD-1 siRNA)-NPs with vaccination. Therapeutic doses of antibody $(200 \mu \mathrm{g} / \mathrm{kg})$ and siRNA $(200 \mu \mathrm{g} / \mathrm{kg})$ were intravenously injected into EG7 tumor-bearing mice twice in a week for 3 weeks as shown in figure $6 \mathrm{~A}$. The PLGA (PD-L1 siRNA+PD-1 siRNA)-NPs with vaccination group showed significant inhibition of tumor growth compared with the positive control with vaccination $(89 \%$ decrease, $\mathrm{p}<0.001)$ and anti-PD-L1+antiPD-1 with vaccination $(87 \%$ decrease, $\mathrm{p}<0.001)$ groups (figure 6B). Notably, the tumor weight in the PLGA (PD-L1 siRNA+PD-1 siRNA)-NPs with vaccination group was significantly lower than that in the positive control with vaccination $(80 \%$ decrease, $p<0.001)$ and anti-PDL1+anti-PD-1 with vaccination $(75 \%$ decrease, $\mathrm{p}<0.001)$ groups (figure 6C,D). Additionally, mice treated with PLGA (PD-L1 siRNA+PD-1 siRNA)-NPs showed a $60 \%$ higher survival for at least 50 days as compared with the control and other groups, where all mice died within 45 days (figure 6E).

We next performed flow cytometry and western blot analysis to confirm the expression of PD-L1 and PD-1 in tumor tissues. PD-L1 and PD-1 expression levels were significantly reduced in the PLGA (PD-L1 siRNA)-NPs with vaccination and PLGA (PD-L1 siRNA+PD-1 siRNA)-NPs with vaccination groups as compared with those in the control group (figure $6 \mathrm{~F}-\mathrm{I}$ ). Cytotoxic $\mathrm{CD}^{+} \mathrm{T}$ cells in splenocytes were significantly increased in the PLGA (PD-L1 siRNA+PD-1 siRNA)-NPs with vaccination group as compared with those in the control group $(\mathrm{p}<0.001$, figure 6J). Additionally, we stained the tumor tissues to examine PD-L1 and PD-1 expression, infiltration of CD8 ${ }^{+}$ T cells, cell proliferation, and apoptosis (figure 6K). PLGA (PD-L1 siRNA+PD-1 siRNA)-NPs with vaccination group showed significant inhibition of both PD-L1 $(p<0.001)$ and PD-1 $(p<0.001)$ expression, increased CD8 ${ }^{+}$Tcell infiltration $(p<0.05)$, reduced cell proliferation $(p<0.01)$, and increased apoptosis $(\mathrm{p}<0.001)$ as compared with those in the control group.

Moreover, we assessed the therapeutic efficacy of the treatment of PLGA (PD-L1 siRNA+PD1 siRNA)-NPs and anti-PD-L1+anti-PD-1 to compare the dose-dependent anticancer effect at high doses of antibody as suggested in a clinical protocol. ${ }^{33}$ The dose of siRNA in PLGA (PD-L1 siRNA+PD-1 siRNA)-NPs was used at $200 \mu \mathrm{g} /$ $\mathrm{kg}$, which was the same as that used in this study. AntiPD-L1+anti-PD-1 were used at $10,000 \mu \mathrm{g} / \mathrm{kg}$, which is accepted as the maximum tolerance dose. ${ }^{34}{ }^{35}$ According to the protocol, antibodies (anti-PD-L1+anti-PD-1) were injected once every 2 weeks. Although antibody treatment showed therapeutic efficacy at high doses, PLGA (PD-L1 siRNA+PD-1 siRNA)-NPs significantly inhibited tumor growth compared with the antibody treatment, even at low doses (online supplemental figure S5).

\section{Biochemical toxicity of PLGA (PD-L1 siRNA+PD-1 siRNA)-NPs}

To evaluate the biochemical toxicity of PLGA (PD-L1 siRNA+PD-1 siRNA)-NPs on liver and renal function, we analyzed the levels of relevant biomarkers for AST, ALT, and BUN in the serum of mice treated with PLGA (PD-L1 siRNA+PD-1 siRNA)-NPs. There were no significant differences in the AST, ALT, and BUN levels between PLGA (PD-L1 siRNA+PD-1 siRNA)-NP-treated group and the control group (figure 7A). Moreover, H\&E staining of vital organs was performed to determine the toxicity induced on PLGA (PD-L1 siRNA+PD-1 siRNA)-NP treatment. The histological structures of the organs treated with PLGA (PD-L1 siRNA+PD-1 siRNA)-NPs were similar to those of the control group, indicating no differences in pathological observations (figure 7B).

\section{DISCUSSION}

This study demonstrates the potential of PLGA (PD-L1 siRNA+PD-1 siRNA)-NPs as a novel immunotherapeutic approach for silencing immune checkpoints and a replacement for the existing antibody-based cancer immunotherapies. In the present study, we confirmed the presence of secreted PD-L1 from tumor cells, which is an important issue for the limited use of antibody-based approaches in cancer therapy. To overcome this hurdle, we suggested siRNA-encapsulated PLGA (siRNA)-NP systems and silenced PD-L1 expression in tumor cells, which effectively prevented PD-L1 secretion from tumor cells. Additionally, we demonstrated the therapeutic efficacy of NP-based therapeutic vaccines, which showed significant inhibition of tumor growth to enhance the tumor antigen-specific cytotoxic $\mathrm{CD}^{+}$Tcell response. Consequently, our system provides a synergistic therapeutic potential for cancer immunotherapy.

Cancer immunotherapy is one of the most promising approaches for cancer treatment. Among these approaches, immune checkpoint inhibition using antibodies (anti-PD-1, anti-PD-L1, and anti-CTLA4) offers clinical benefits and can be applied to many cancer types. ${ }^{36}{ }^{37}$ Although the role of immune checkpoint function via immune evasion mechanisms in the tumor microenvironment is well known, the use of antibody-based blockades has been shown to increase the incidence of acquired resistance to antibodies, and such issues have been reported by several groups. ${ }^{38}{ }^{39}$ Moreover, effectiveness is only observed in a small fraction of patients, and resistance after initial response is commonly observed. ${ }^{13}$ One major problem that leads to decreasing therapeutic efficacy using anti-PD-L1 or anti-PD-1 is that the immune checkpoint molecules can be released from tumor cells in a soluble form, rather than a membrane-bound form. ${ }^{12}$ In the soluble form, these molecules can suspend and 
A

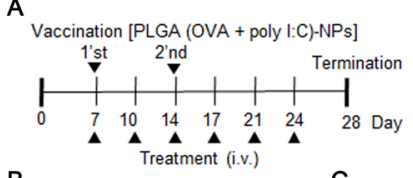

B

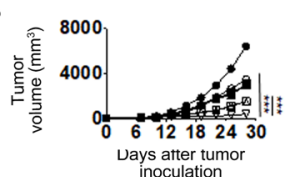

C

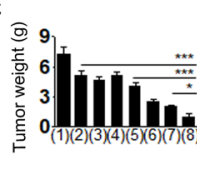

(1); - Control without vaccination

; Control with vaccination

Anti-PD-1 with vaccination

; Anti-PD-L1+PD-1 with vaccination

; $\mathrm{PLGA}(\mathrm{PD}-\mathrm{L} 1 \mathrm{siRNA})-\mathrm{NP}$ with vaccination

$\nabla$ PLGA (PD-L1 SIRNA + PD-1 SIRNA)-NP

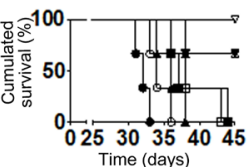

D
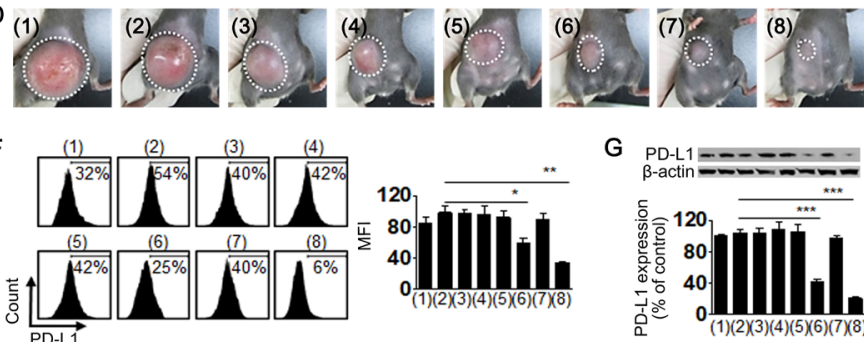

G PD-L1-ニactin
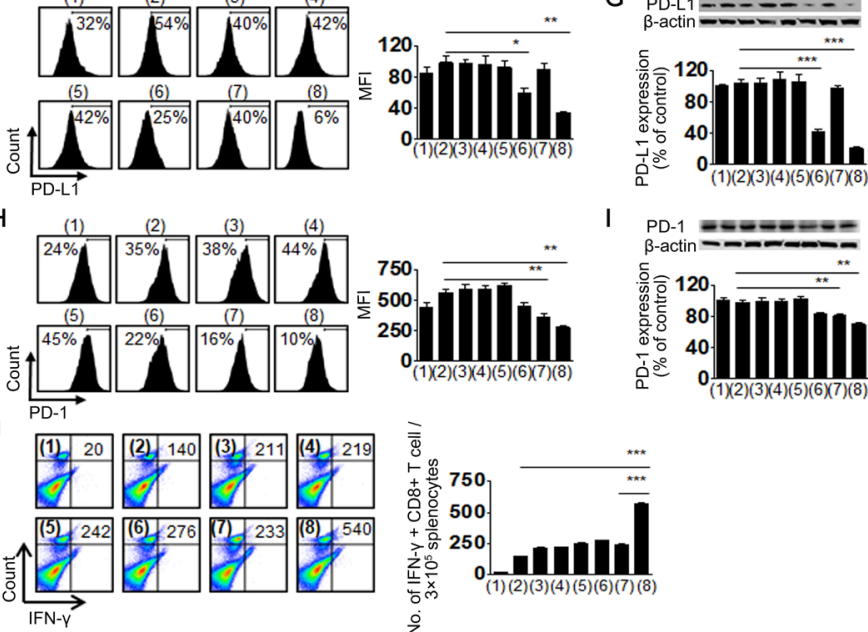

I PD-1 =-1 $\mathrm{P}$-actin
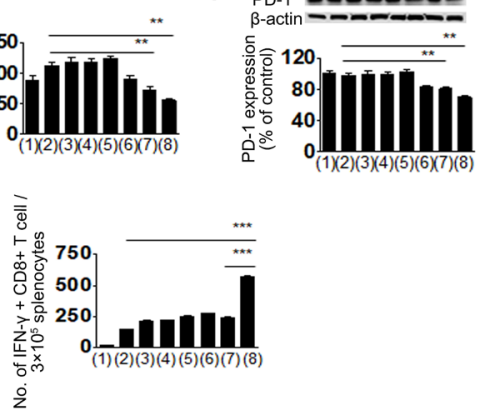
א (1)
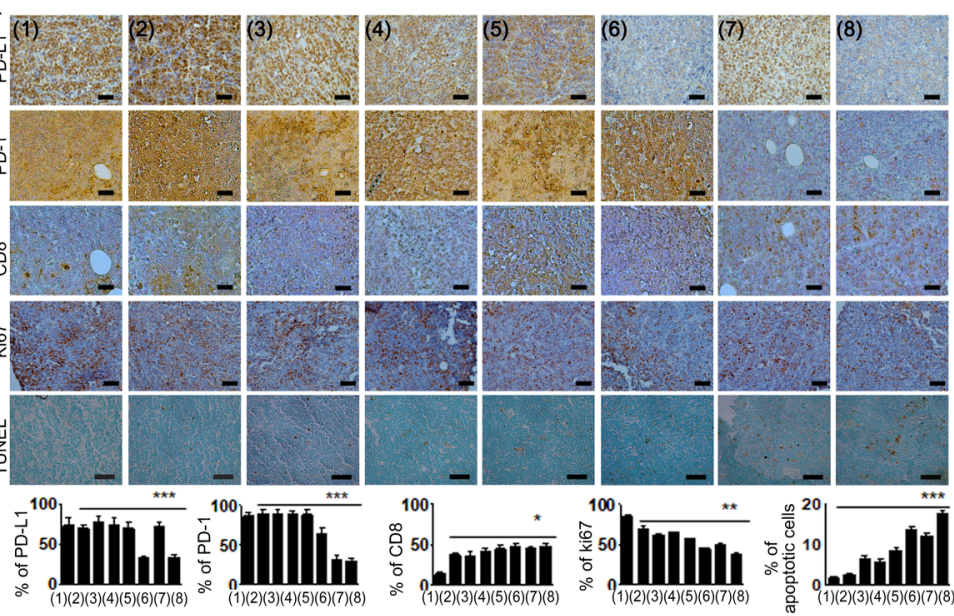

Figure 6 Therapeutic efficacy of poly(lactic-co-glycolic acid) (PLGA) (small interfering RNA (siRNA))-nanoparticles (NPs) against EG7 tumor-bearing mouse model. Treatment began 1 week after subcutaneous injection of EG7 cells into the mice ( $n=5 /$ group). PLGA (ovalbumin (OVA)+poly I:C)-NPs were administered once per week for 2 weeks by means of subcutaneous injection. The PLGA (programmed death ligand 1 (PD-L1) siRNA+programmed cell death 1 (PD-1) siRNA)-NPs with vaccination group was injected twice per week for 3 weeks by means of intravenous injection ( $200 \mu \mathrm{g} / \mathrm{kg}$ of siRNA or antibody).

(A) Experimental schedule. (B) Tumor volume, (C) tumor weight, and (D) images of mice. (E) Survival of treated mice. (F, G) PDL1 expression in the tumor tissues was examined using flow cytometry and western blot analysis. (H, I) PD-1 expression in the tumor tissues was examined using flow cytometry and western blot analysis. $(\mathrm{J})$ Cytotoxic $\mathrm{CD}^{+} \mathrm{T}$ cells in the splenocytes were counted using flow cytometry. The bar graph indicates the number of CD8 ${ }^{+}$and interferon (IFN)- $\gamma+$ cells $/ 3 \times 10^{5}$ splenocytes. (K) Immunohistochemical analysis for expression of PD-L1 (anti-PD-L1) and PD-1 (anti-PD-1), infiltration of CD8 ${ }^{+}$Tcell (antiCD8), cell proliferation (anti-Ki67), and apoptosis (Terminal deoxynucleotidyl transferase dUTP nick end labeling (TUNEL) assay) (scale bar: $50 \mu \mathrm{m}$ ). Error bars represent the SEM. ${ }^{*} \mathrm{P}<0.05,{ }^{* \star} \mathrm{p}<0.01$, and ${ }^{* \star *} \mathrm{p}<0.001$. 
A

B
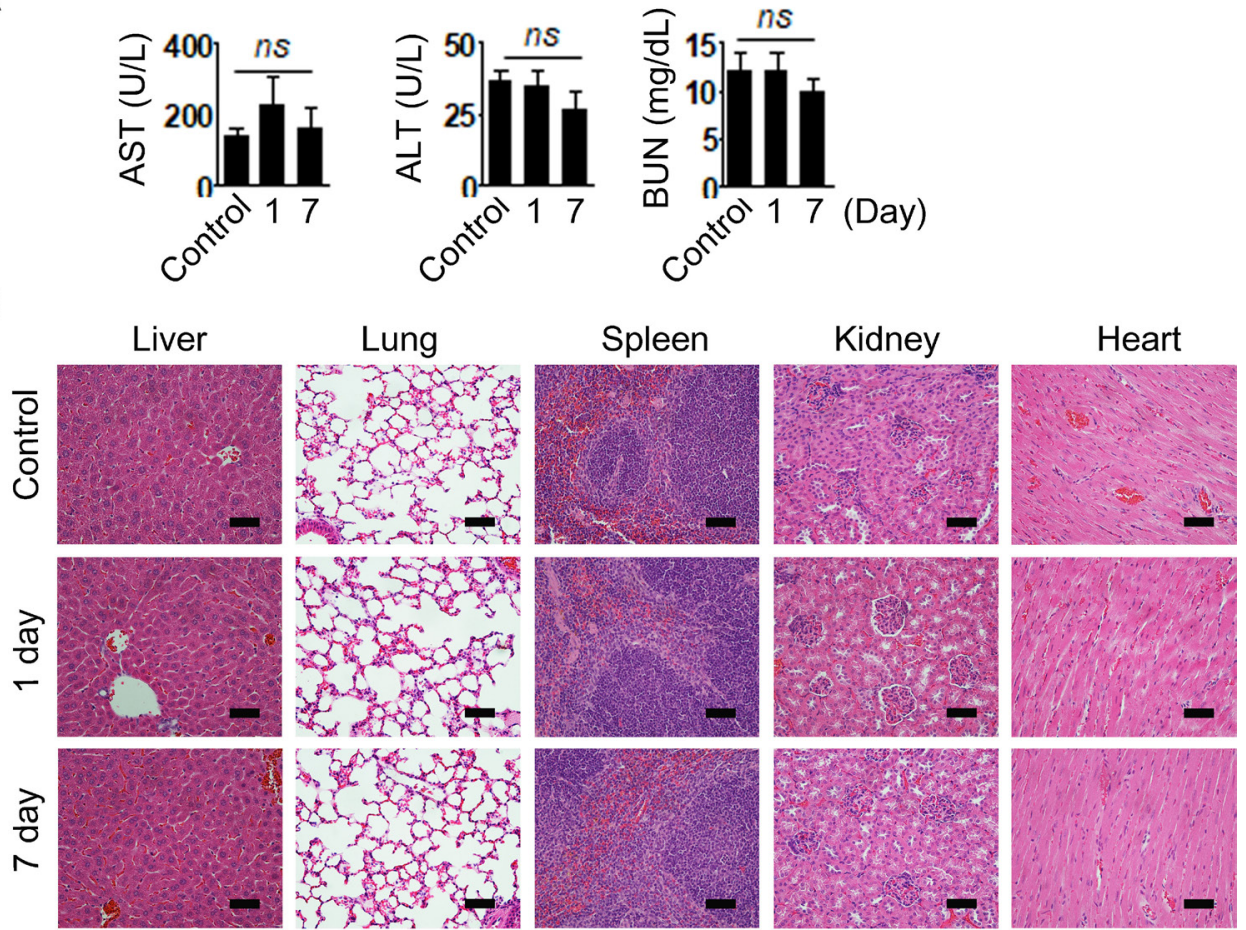

Figure 7 Biochemical toxicity of poly(lactic-co-glycolic acid) (PLGA) (programmed death ligand 1 (PD-L1) small interfering RNA (siRNA)+programmed cell death 1 (PD-1) siRNA)-nanoparticles (NPs). (A) Levels of aminotransferase (AST), alanine aminotransferase (ALT), and blood urea nitrogen (BUN) were evaluated using diagnostic kits in the serum of mice injected with PLGA (PD-L1 siRNA+PD-1 siRNA)-NPs. (B) H\&E staining of the major organs (scale bar: $50 \mu \mathrm{m}$ ). Error bars represent the SEM $(n=3)$. ns, not significant.

circulate in the tumor microenvironment. Meanwhile, antibody blockades such as anti-PD-L1 and anti-PD-1 can bind to these secreted immune checkpoint molecules, leading to decreased antibody-based therapeutic outcomes. ${ }^{140}$ Patients with higher expression of soluble PD-L1 and PD-1 exhibited shorter overall survival rates and tumor-free survival than those with lower expression. These results indicate that patients with higher soluble PD-1 and PD-L1 levels have worse prognosis. ${ }^{41}{ }^{42}$ These are critical points for the development of therapeutics for broad cancer types. Therefore, we focused on an immune checkpoint silencing system based on siRNA as a novel approach to prevent immune suppressive binding of PD-1 or PD-L1 to anti-PD-1 or anti-PD-L1, respectively. The results of the study demonstrated that there is an increase in therapeutic efficacy on fundamentally inhibiting the secretion of immune checkpoint molecules.

siRNA-based approaches are attractive strategies for knocking-down target molecules. ${ }^{43}$ Moreover, these may allow for the development of a broad medicinal application for silencing target genes. However, one of the hurdles limiting the therapeutic application of siRNA is the need for an efficient delivery system because siRNA alone is rapidly cleared or degraded by nucleases in the body. Recently, NP-based carrier systems have been extensively developed to increase the delivery efficiency of siRNAs. These are highly attractive for cancer therapy because of their specific capacities and biocompatibility. In addition, NPs increase the therapeutic dose at disease sites, thereby minimizing unexpected side effects. In this study, we selected PLGA polymer as an NP matrix, which is particularly attractive for clinical and biological applications, given its low toxicity, low immunogenicity, biocompatibility, and biodegradability. ${ }^{21}$

Combination therapies for cancer have been considered to increase synergistic therapeutic outcomes by integrating two or more therapeutic agents. ${ }^{44}$ As a novel strategy for cancer immunotherapy, a combination of immune checkpoint blockades has been applied to treat many cancer types, which shows greater therapeutic benefit as compared with monotherapies, because it prevents an immunosuppressive response. Based on this study, we propose a combination strategy that uses PLGA (PD-L1 siRNA+PD-1 siRNA)-NPs as an immune checkpoint silencing system alongside NP-based vaccines, which demonstrated promising synergistic effects for the treatment of cancer. NP-based vaccines offer a rational approach to improving safety and reducing the toxicity of adjuvants. In addition, the NP system can further enhance antigen-specific $\mathrm{CD}^{+}$Tcell activation and immune response without increasing toxicity, by allowing for synergy with therapeutic payloads, such as antigens or adjuvants. Therefore, in this study, we used a PLGA (tumor antigen+adjuvant)-NP system in combination with PLGA (PD-L1 siRNA+PD-1 siRNA)-NPs to induce antigen-specific $\mathrm{CD} 8^{+} \mathrm{T}$ cell-based immune responses. ${ }^{22}$

In summary, we focused on the development of an siRNA-based immune checkpoint silencing system to 
enhance the therapeutic unmet need to improve on antibody-based cancer immunotherapy. Our results provide a novel approach to target gene silencing of immune checkpoints in the tumor microenvironment. Consequently, our study revealed a novel understanding of an siRNA-based cancer immunotherapeutic approach as a nanomedicine platform.

\section{Author affiliations}

${ }^{1}$ Department of Immunology, Konkuk University School of Medicine, Chungju, The Republic of Korea

${ }^{2}$ Department of Obstertrics and Gynecology, Samsung Medical Center,

Sungkyunkwan University, Seoul, The Republic of Korea

${ }^{3}$ Department of Integrative Bioscience and Biotechnology, Sejong University, Gwangjin-gu, The Republic of Korea

Contributors HDH and Y-MP conceived and supervised the study. JEW and YB performed most of the experiments and analyzed the data. TIW, CML, and JHL developed the NP system and performed the in vitro and in vivo experiments. THK and J-WL analyzed the in vitro and in vivo experiments. HDH, JEW, and YJL helped with the overall concept and reviewed the manuscript. HDH is responsible for the overall content as guarantor.

Funding This work was supported by the National Research Foundation of Korea (NRF) grant funded by the Korean government (NRF-2016R1A5A2012284 to Y-MP, and NRF-2019R1A2C1085144 and NRF-2020M3A9G3080282 to HDH).

Competing interests None declared.

Patient consent for publication Not applicable.

Ethics approval Female C57BL/6 mice were maintained according to the protocols approved by the Konkuk University Institutional Animal Care and Use Committee (ref. no.: KU19231-2). All procedures were performed according to the approved protocols and recommendations for the proper use and care of animals at the specific pathogen-free housing facility of Konkuk University. This study does not involve human participants.

Provenance and peer review Not commissioned; externally peer reviewed.

Data availability statement Data are available in a public, open access repository.

Supplemental material This content has been supplied by the author(s). It has not been vetted by BMJ Publishing Group Limited (BMJ) and may not have been peer-reviewed. Any opinions or recommendations discussed are solely those of the author(s) and are not endorsed by BMJ. BMJ disclaims all liability and responsibility arising from any reliance placed on the content. Where the content includes any translated material, BMJ does not warrant the accuracy and reliability of the translations (including but not limited to local regulations, clinical guidelines, terminology, drug names and drug dosages), and is not responsible for any error and/or omissions arising from translation and adaptation or otherwise.

Open access This is an open access article distributed in accordance with the Creative Commons Attribution 4.0 Unported (CC BY 4.0) license, which permits others to copy, redistribute, remix, transform and build upon this work for any purpose, provided the original work is properly cited, a link to the licence is given, and indication of whether changes were made. See https://creativecommons.org/ licenses/by/4.0/.

\section{ORCID iDs}

Tae Heung Kang http://orcid.org/0000-0002-9853-913X

Hee Dong Han http://orcid.org/0000-0002-3300-5575

\section{REFERENCES}

1 Zhang $\mathrm{Y}$, Zhang $\mathrm{Z}$. The history and advances in cancer immunotherapy: understanding the characteristics of tumorinfiltrating immune cells and their therapeutic implications. Cell Mol Immunol 2020;17:807-21.

2 Waldman AD, Fritz JM, Lenardo MJ. A guide to cancer immunotherapy: from T cell basic science to clinical practice. Nat Rev Immunol 2020;20:651-68.

3 Hargadon KM, Johnson CE, Williams CJ. Immune checkpoint blockade therapy for cancer: an overview of FDA-approved immune checkpoint inhibitors. Int Immunopharmacol 2018;62:29-39.
4 Peng Q, Qiu X, Zhang Z, et al. PD-L1 on dendritic cells attenuates $T$ cell activation and regulates response to immune checkpoint blockade. Nat Commun 2020;11:4835.

5 Yu W, Hua Y, Qiu H, et al. PD-L1 promotes tumor growth and progression by activating WIP and $\beta$-catenin signaling pathways and predicts poor prognosis in lung cancer. Cell Death Dis 2020;11:506.

6 Rosenbaum MW, Bledsoe JR, Morales-Oyarvide V, et al. PD-L1 expression in colorectal cancer is associated with microsatellite instability, BRAF mutation, medullary morphology and cytotoxic tumor-infiltrating lymphocytes. Mod Pathol 2016;29:1104-12.

7 Yang J, Dong M, Shui Y, et al. A pooled analysis of the prognostic value of PD-L1 in melanoma: evidence from 1062 patients. Cancer Cell Int 2020;20:96.

8 van Ens D, Mousset CM, Hutten TJA, et al. PD-L1 siRNA-mediated silencing in acute myeloid leukemia enhances anti-leukemic $T$ cell reactivity. Bone Marrow Transplant 2020;55:2308-18.

9 Yao H, Wang H, Li C, et al. Cancer cell-intrinsic PD-1 and implications in combinatorial immunotherapy. Front Immunol 2018;9:9.

10 Kleffel S, Posch C, Barthel SR, et al. Melanoma cell-intrinsic PD-1 receptor functions promote tumor growth. Cell 2015;162:1242-56.

11 Tovoli F, De Lorenzo S, Trevisani F. Immunotherapy with checkpoint inhibitors for hepatocellular carcinoma: where are we now? Vaccines 2020;8. doi:10.3390/vaccines8040578. [Epub ahead of print: 02 Oct 2020].

12 Poggio M, Hu T, Pai C-C, et al. Suppression of exosomal PDL1 induces systemic anti-tumor immunity and memory. Cell 2019;177:414-27.

13 Nagato T, Ohkuri T, Ohara K, et al. Programmed death-ligand 1 and its soluble form are highly expressed in nasal natural killer/T-cell Iymphoma: a potential rationale for immunotherapy. Cancer Immunol Immunother 2017;66:877-90.

14 Gong B, Kiyotani K, Sakata S, et al. Secreted PD-L1 variants mediate resistance to PD-L1 blockade therapy in non-small cell lung cancer. $J$ Exp Med 2019;216:982-1000.

15 Hu B, Zhong L, Weng Y, et al. Therapeutic siRNA: state of the art. Signal Transduct Target Ther 2020;5:101.

16 Kim B, Park J-H, Sailor MJ. Rekindling RNAi therapy: materials design requirements for in vivo siRNA delivery. Adv Mater 2019;31:e1903637:1903637.

17 Sadat Tabatabaei Mirakabad F, Nejati-Koshki K, Akbarzadeh A, et al. PLGA-based nanoparticles as cancer drug delivery systems. Asian Pac J Cancer Prev 2014;15:517-35.

18 Joshi VB, Geary SM, Salem AK. Biodegradable particles as vaccine antigen delivery systems for stimulating cellular immune responses. Hum Vaccin Immunother 2013;9:2584-90.

19 Dong X, Liang J, Yang A, et al. A visible codelivery nanovaccine of antigen and adjuvant with self-carrier for cancer immunotherapy. ACS Appl Mater Interfaces 2019;11:4876-88.

20 Shao K, Singha S, Clemente-Casares X, et al. Nanoparticle-based immunotherapy for cancer. ACS Nano 2015;9:16-30.

21 Byeon Y, Lee J-W, Choi WS, et al. CD44-Targeting PLGA nanoparticles incorporating paclitaxel and FAK siRNA overcome chemoresistance in epithelial ovarian cancer. Cancer Res 2018;78:6247-56.

22 Han HD, Byeon Y, Kang TH, et al. Toll-like receptor 3-induced immune response by poly(d,I-lactide-co-glycolide) nanoparticles for dendritic cell-based cancer immunotherapy. Int J Nanomedicine 2016;11:5729-42.

23 Kwon HJ, Byeon Y, Jeon HN, et al. Gold cluster-labeled thermosensitive liposmes enhance triggered drug release in the tumor microenvironment by a photothermal effect. $J$ Control Release 2015;216:132-9.

24 Grebe KM, Hickman HD, Irvine KR, et al. Sympathetic nervous system control of anti-influenza CD8+ T cell responses. Proc Natl Acad Sci U S A 2009;106:5300-5.

25 Klement JD, Paschall AV, Redd PS, et al. An osteopontin/CD44 immune checkpoint controls CD8+ T cell activation and tumor immune evasion. J Clin Invest 2018;128:5549-60.

26 Eckhardt BL, Parker BS, van Laar RK, et al. Genomic analysis of a spontaneous model of breast cancer metastasis to bone reveals a role for the extracellular matrix. Mol Cancer Res 2005;3:1-13.

$27 \mathrm{Kim} \mathrm{GH}$, Won JE, Byeon Y, et al. Selective delivery of PLXDC1 small interfering RNA to endothelial cells for anti-angiogenesis tumor therapy using CD44-targeted chitosan nanoparticles for epithelial ovarian cancer. Drug Deliv 2018;25:1394-402.

28 Hudson K, Cross N, Jordan-Mahy N, et al. The extrinsic and intrinsic roles of PD-L1 and its receptor PD-1: implications for immunotherapy treatment. Front Immunol 2020;11:568931.

29 Daassi D, Mahoney KM, Freeman GJ. The importance of exosomal PDL1 in tumour immune evasion. Nat Rev Immunol 2020;20:209-15. 
$30 \mathrm{Kim}$ EH, Suresh M. Role of PI3K/Akt signaling in memory CD8 T cell differentiation. Front Immunol 2013;4:20.

31 Smalley Rumfield C, Pellom ST, Morillon li YM, et al. Immunomodulation to enhance the efficacy of an HPV therapeutic vaccine. J Immunother Cancer 2020;8:e000612.

$32 \mathrm{Hu}$ Z, Ott PA, Wu CJ, . Towards personalized, tumour-specific, therapeutic vaccines for cancer. Nat Rev Immunol 2018;18:168-82.

33 Renner A, Burotto M, Rojas C. Immune checkpoint inhibitor dosing: can we go lower without compromising clinical efficacy? J Glob Oncol 2019;5:1-5.

34 Patnaik A, Kang SP, Rasco D, et al. Phase I study of pembrolizumab (MK-3475; anti-PD-1 monoclonal antibody) in patients with advanced solid tumors. Clin Cancer Res 2015;21:4286-93.

35 Brahmer JR, Tykodi SS, Chow LQM, et al. Safety and activity of anti-PD-L1 antibody in patients with advanced cancer. N Engl J Med 2012;366:2455-65.

36 Santos-Briz A, Cañueto J, Carmen SD, et al. Value of PD-L1, PD-1, and CTLA-4 expression in the clinical practice as predictors of response to nivolumab and ipilimumab in monotherapy in patients with advanced stage melanoma. Am J Dermatopathol 2021;43:423-8.

37 Jacquelot N, Roberti MP, Enot DP, et al. Predictors of responses to immune checkpoint blockade in advanced melanoma. Nat Commun $2017 ; 8: 592$.
38 Barrueto L, Caminero F, Cash L, et al. Resistance to checkpoint inhibition in cancer immunotherapy. Trans/ Oncol 2020;13:100738.

39 Riley RS, June CH, Langer R, et al. Delivery technologies for cancer immunotherapy. Nat Rev Drug Discov 2019;18:175-96.

40 Asanuma K, Nakamura T, Hayashi A, et al. Soluble programmed death-ligand 1 rather than PD-L1 on tumor cells effectively predicts metastasis and prognosis in soft tissue sarcomas. Sci Rep 2020;10:9077.

41 Rossille D, Gressier M, Damotte D, et al. High level of soluble programmed cell death ligand 1 in blood impacts overall survival in aggressive diffuse large B-cell lymphoma: results from a French multicenter clinical trial. Leukemia 2014;28:2367-75.

42 Zeng Z, Shi F, Zhou L, et al. Upregulation of circulating PD-L1/ $\mathrm{PD}-1$ is associated with poor post-cryoablation prognosis in patients with HBV-related hepatocellular carcinoma. PLoS One 2011;6:e23621.

43 de Fougerolles A, Vornlocher H-P, Maraganore J, et al. Interfering with disease: a progress report on siRNA-based therapeutics. Nat Rev Drug Discov 2007;6:443-53.

44 Barbari C, Fontaine T, Parajuli P, et al. Immunotherapies and combination strategies for Immuno-Oncology. Int $J \mathrm{Mol} \mathrm{Sci}$ 2020;21. doi:10.3390/ijms21145009. [Epub ahead of print: $15 \mathrm{Jul}$ 2020]. 